\title{
A buprenorphine-validated rat model of opioid use disorder optimized to study sex differences in vulnerability to relapse
}

\author{
Anousheh Bakhti-Suroosh ${ }^{1}$ • Eleanor Blair Towers ${ }^{1} \cdot$ Wendy J. Lynch $^{1}$ \\ Received: 13 August 2020 / Accepted: 8 December 2020 / Published online: 6 January 2021 \\ (C) Springer-Verlag GmbH Germany, part of Springer Nature 2021
}

\begin{abstract}
Rationale Opioid use disorder (OUD) is a major epidemic in the USA. Despite evidence indicating that OUD may be particularly severe for women, preclinical models have yet to establish sex as a major factor in OUD.

Objectives Here, we examined sex differences in vulnerability to relapse following intermittent access fentanyl selfadministration and protracted abstinence and used buprenorphine, the FDA-approved treatment for OUD, to test the validity of our model.

Methods Following acquisition of fentanyl self-administration under one of two training conditions, male and female rats were given extended, $24-\mathrm{h} /$ day access to fentanyl $(0.25 \mu \mathrm{g} / \mathrm{kg} /$ infusion, 10 days $)$ using an intermittent access procedure. Vulnerability to relapse was assessed using an extinction/cue-induced reinstatement procedure following 14 days of abstinence; buprenorphine ( 0 or $3 \mathrm{mg} / \mathrm{kg} /$ day) was administered throughout abstinence.

Results Levels of drug-seeking were high following extended-access fentanyl self-administration and abstinence; buprenorphine markedly decreased drug-seeking supporting the validity of our relapse model. Females self-administered more fentanyl and responded at higher levels during subsequent extinction testing. Buprenorphine was effective in both sexes and eliminated sex and estrous phase differences in drug-seeking. Interestingly, the inclusion of a time-out during training had a major impact on later fentanyl self-administration in females, but not males, indicating that the initial exposure conditions can persistently impact vulnerability in females.
\end{abstract}

Conclusions These findings demonstrate the utility of this rat model for determining sex and hormonal influences on the development and treatment of OUD.

Keywords Addiction-like phenotype $\cdot$ Fentanyl $\cdot$ Opioid $\cdot$ Intermittent access $\cdot$ Self-administration $\cdot$ Sex differences · Buprenorphine · Treatment

\section{Introduction}

Opioid use disorder (OUD) is a major epidemic in the USA. In 2018 alone, 67,367 Americans died from a drug overdose, roughly 185 individuals every day, and synthetic opioids, such as fentanyl, were a major culprit (Hedegaard et al. 2020). In addition, as the COVID-19 global pandemic continues, there are concerns that the opioid epidemic is worsening with reports from national, state, and local media suggesting an increase in opioid-related mortality in more than 30

Wendy J. Lynch

wlynch@virginia.edu

1 Department of Psychiatry and Neurobehavioral Sciences, University of Virginia, P.O. Box 801402, Charlottesville, VA 22904, USA states, particularly from illicitly manufactured fentanyl and fentanyl analogs (American Medical Association 2020). Effects of the opioid epidemic are widespread, and women are at a particularly high risk (Hemsing et al. 2016; Koons et al. 2018; Mazure and Fiellin 2018; Huhn et al. 2019) as they are more likely than men to be prescribed opioids and to misuse prescription opioids (Koons et al. 2018; Hirschtritt et al. 2018). Although men have historically had higher rates of OUD than women, differences have narrowed in the current opioid epidemic (i.e., 2.3:1 male-to-female ratio in 2002 versus a 1.8:1 ratio in 2018; National Survey on Drug Use and Health 2020) with use increasing at a faster rate in women versus men (i.e., $283 \%$ versus $108 \%$ increase in heroin use from 2007 to 2014; Marsh et al. 2018; Mazure and Fiellin 2018). Women also develop OUD after less drug exposure/ fewer years of drug use than men; this phenomenon has been 
termed the telescoping effect and has been reported for opioids as well as other substances (e.g., cocaine, cannabis, alcohol; Anglin et al. 1987; Hser et al. 1987a, 1987b; Haas and Peters 2000; Hernandez-Avila et al. 2004; Back et al. 2011a, 2011 b; Sartor et al. 2014; Lewis et al. 2014). While sociocultural factors likely contribute to some of these differences (Office of Women's Health 2017), it is also possible that biological factors contribute although few studies have examined this possibility.

Despite differences between men and women in vulnerability to OUD, most preclinical studies on OUD have focused on males. In addition, of the studies that have examined sex differences most have focused on vulnerability to drug use, and thus early phases of the addiction process, such as acquisition and drug intake under short access conditions (e.g., Lynch and Carroll 1999; Thorpe et al. 2020). In general, these findings indicate that females have an enhanced sensitivity to the reinforcing effects of opioids in that they acquire heroin self-administration faster and are more motivated to obtain infusions of fentanyl, heroin, remifentanil, and morphine as compared to males (Ambrosio et al. 1999; Carroll et al. 2002; Cicero et al. 2003; González et al. 2003; Klein et al. 1997; Lacy et al. 2016; Lynch and Carroll 1999; Thorpe et al. 2020; Townsend et al. 2019; Vela et al. 1998; but see Stewart et al. 1996). Some studies have also observed higher opioid intake in females than males under short access conditions (Biscaia et al. 2008; Carroll et al. 2001, 2002; Cicero et al. 2003; Fulenwider et al. 2019; Phillips et al. 2019) although other studies have reported similar intake between the sexes (Gipson et al. 2020; Mavrikaki et al. 2017; Smethells et al. 2020; Vazquez et al. 2020; Zhang et al. 2018). These preclinical results are also consistent with findings in humans showing that women with an OUD report greater positive subjective effects following opioid use than men (i.e., liking, feeling high, street value); notably, these enhanced positive reports occurred even in the face of enhanced negative subjective/ physical effects (enhanced nausea and vomiting; Lofwall et al. 2012; also see Zacny 2002).

Much less is known regarding sex differences in vulnerability during later stages of the addiction process, and more specifically, following the development of an addiction-like phenotype. Several different procedures have been developed to induce an addiction-like phenotype in rats, such as an enhanced motivation to use the drug, use despite negative consequences, and vulnerability to relapse (Lynch 2018). Extended access drug self-administration, which results in escalating and/or binge patterns of use, appears to be critical for inducing addiction-like characteristics (Ahmed et al. 2000; Koob 2020; Lynch 2018). These characteristics also tend to emerge over abstinence and to increase, or "incubate," over time (Grimm et al. 2001; Gancarz-Kausch et al. 2014). Results with other drugs of abuse demonstrate that in females, these characteristics are more robustly expressed (Nicolas et al.
2019; Reichel et al. 2012) and develop sooner during abstinence and/or following less drug exposure as compared to males (Lynch and Taylor 2004; Ramôa et al. 2013, 2014; Perry et al. 2013; Lynch 2018). Similar effects may also occur with opioids considering findings showing that female rats and mice given extended access ( $\geq 6 \mathrm{~h} /$ day) to heroin or oxycodone self-administer more drug and/or show greater escalation of intake over time than their male counterparts (Carroll et al. 2002; Towers et al. 2019; Kimbrough et al. 2020). However, sex differences with opioids may be less robust than with other drugs given that several other studies have reported no differences between males and females in levels or patterns of drug intake under extended access conditions (Venniro et al. 2017, 2019; Reiner et al. 2020) or for subsequent levels of drug-seeking following voluntary (Reiner et al. 2020) or forced abstinence (Venniro et al. 2019). One the other hand, it is possible that sex differences were obscured in these latter studies given that intake was restricted in each of these studies to either 12 (Reiner et al. 2020) or 15 infusions/h (Fredriksson et al. 2020; Venniro et al. 2017, 2019). These latter studies also included choice testing between heroin/fentanyl and a non-drug reward within the extended access training period which may have impacted the occurrence of sex differences as well as the development of an addiction-like phenotype. Indeed, the main findings from three of these studies was that, like contingency management in humans, the availability of a non-drug reward (palatable food or social interaction) could be used to maintain voluntary abstinence and reduce/prevent the development of incubated drug-craving (Reiner et al. 2020; Venniro et al. 2017, 2019). This interpretation is also consistent with their findings showing that both males and females showed a high preference for the non-drug versus drug reward even when tested following protracted abstinence (Reiner et al. 2020; Venniro et al. 2017, 2019).

The purpose of the present study was to examine sex differences in the development of an addiction-like phenotype with opioids using conditions optimized for its development (extended access self-administration without limits on intake and protracted abstinence without the inclusion of alternative non-drug rewards). We focused on vulnerability to relapse as assessed following extended access fentanyl selfadministration and protracted abstinence (14 days), when levels of drug-seeking are known to be high (Grimm et al. 2001). To do so, rats were first trained to self-administer fentanyl under one of two training conditions, with or without a time-out after each infusion, and then were given extended, 24-h/day access to fentanyl using an intermittent access procedure known to induce an addiction-like phenotype (Fragale et al. 2020; Martin et al. 2020; O’Neal et al. 2020; also see Zimmer et al. 2012). As a test of validity for our behavioral phenotype as a rat model of relapse, we also examined the efficacy of daily treatment during abstinence with buprenorphine, an FDA-approved treatment for OUD in 
humans, to attenuate drug-seeking. This experiment also allowed us to examine sex differences in the efficacy of buprenorphine as an anti-relapse intervention which is important since sex/gender differences in humans are difficult to interpret (Hecksher and Hesse 2009; Tuchman 2010; McHugh et al. 2013; Koons et al. 2018). We hypothesized that, as in humans, female rats would show an enhanced vulnerability to developing an addiction-like phenotype, including greater intake and seeking, and that buprenorphine treatment would decrease fentanyl-seeking in both males and females.

\section{Materials and methods}

\section{Subjects}

Subjects were sexually mature male $(N=41)$ and female $(N=$ 54) Sprague-Dawley rats (Charles River), weighing approximately $370 \mathrm{~g}$ (male) and $270 \mathrm{~g}$ (female) at the start of the study. Rats were individually housed in operant testing chambers (Med Associates, St. Albans, VT, USA) on arrival and remained in these chambers throughout the experiments. Rats had ad libitum access to water and food (Teklad LM-4857912; except as noted below for some animals during fentanyl selfadministration training) and were maintained on a 12-h light/ dark cycle (lights on at $7 \mathrm{AM}$ ). To ensure rapid acquisition of fentanyl self-administration, rats were pre-trained to leverpress for sucrose pellets $(45 \mathrm{mg})$ in two to three, $24-\mathrm{h} /$ day sessions as described previously (fixed-ratio 1; Lynch 2008). Rats were weighed three times/week, bedding and water bottles were changed two times/week, and health was monitored daily throughout the study. All procedures were conducted within animal care guidelines set by the National Institute of Health and were approved by The University of Virginia Animal Care and Use Committee.

\section{Procedure}

\section{Surgery and catheter maintenance}

Rats were anesthetized with ketamine/dexdomitor and implanted with an indwelling catheter (Silastic tubing, 0.51 and $0.94 \mathrm{~mm}$ o.d.; Dow Corning, Midland, MI, USA) into the right jugular vein using methods previously described (Lynch 2008). Ketoprofen $(2-5 \mathrm{mg} / \mathrm{kg}$, s.c.) and gentamicin $(5.5 \mathrm{mg} / \mathrm{kg}$, i.v.) were administered immediately following surgery and for 2 days following surgery. Catheters were flushed with heparinized saline 3 days/week to verify and help maintain patency. Patency was also verified periodically by administering methohexital $(1.5 \mathrm{mg} / \mathrm{kg})$. If a catheter was no longer patent (i.e., the catheter was leaking, pressure prevented flushing, or the animal did not lose the righting reflex immediately after methohexital), a new catheter was implanted into the left jugular vein with testing resuming following a 1-2-day recovery period.

\section{Fentanyl self-administration training}

Rats were trained to self-administer fentanyl $(0.25 \mu \mathrm{g} / \mathrm{kg} /$ infusion) under a fixed-ratio 1 schedule and one of two training conditions: with a 1-s time-out after each infusion (time-out; $n=20$ males; $n=30$ females) or without a timeout after each infusion (no time-out; $n=21$ males; $n=24$ females; Fig. 1). We initially conducted these studies without a time-out after infusions, but due to concerns of toxicity, particularly in females, we added a brief 1-s time-out to prevent fentanyl overdose. However, with this change, we noticed some changes in behavior during training and extended access self-administration, so we expanded the studies to fully explore the effects of training with and without a 1-s time-out. Both conditions were tested contemporaneously. We selected a low-to-moderate dose of fentanyl $(0.25 \mu \mathrm{g} / \mathrm{kg} /$ infusion $)$ since such doses are sensitive to changes in intake over time and to individual differences (e.g., Morgan et al. 2002). This dose has also been shown to maintain moderate-to-high levels of responding under a progressive-ratio schedule (Awasaki et al. 1997) and to induce robust escalation of intake, with limited toxicity, when available under extended access conditions (12-h/day, fixed-ratio 1; Morgan et al. 2002; also see Nishida et al. 1989; Martin et al. 1997). Pilot data from our laboratory also show that this dose induces rapid and maximal rates of acquisition in both males and females with $>90 \%$ of the rats meeting the acquisition criterion within the first 2-4 days. Sessions began at 12 PM daily with the introduction of the left (active) lever into the chamber and one priming infusion of fentanyl. During the session, each response on the left lever produced a rapidly delivered $(\sim 1 \mathrm{~s})$ infusion of fentanyl which was paired with the sound of the pump and the illumination of a stimulus light above the lever; responses made during an infusion or the 1-s time-out (for the timeout groups) were recorded but had no consequence. Response on the right lever (non-active) were also recorded but had no programmed consequence. The left lever remained extended into the chamber until 40 infusions were obtained or until $11 \mathrm{Am}$ the next day. If a rat did not begin self-administering fentanyl within the first five training sessions, in order to expedite acquisition, it was food restricted to $85 \%$ of its free-feeding body weight until the animal obtained all 40 infusions available for 2 consecutive sessions (generally 2-3 sessions). Training sessions continued daily until acquisition occurred, defined as five consecutive sessions wherein all 40 infusions were obtained (without the use of food restriction). 


\section{SA Training $(\sim 7$ days $) \longrightarrow$ IntA SA (10 days $) \longrightarrow$ [----NoTO or TO----] [--No Time-Out--]}

Fig. 1 Summary of experimental events. Male and female rats were trained to self-administer (SA) fentanyl without (noTO) or with a timeout (TO) after each infusion. Following acquisition of fentanyl SA (5 consecutive sessions wherein all 40 infusions available were obtained), rats were given extended 24-h/day, intermittent access (IntA) to fentanyl $(0.25 \mu \mathrm{g} / \mathrm{kg} /$ infusion $)$ for 10 sessions. No time-outs occurred after infusions during this phase of the study. Following the last IntA fentanyl SA

\section{IntA fentanyl self-administration}

Once rats acquired fentanyl self-administration, they were given extended, 24-h access to fentanyl for 10 consecutive days under an IntA procedure recently developed by Dave Roberts and colleagues (Zimmer et al. 2012). This procedure has already been used fairly extensively with psychostimulants since it readily induces features of an addicted phenotype, including the development of a marked increase in motivation for the drug and vulnerability to relapse as assessed following abstinence (Zimmer et al. 2012; Calipari et al. 2013, 2014, 2015; Calipari and Jones 2014; Kawa et al. 2016; Allain et al. 2017, 2018; Singer et al. 2017; Venniro et al. 2018; Kawa and Robinson 2019; Gueye et al. 2019; Nicolas et al. 2019; Allain and Samaha 2019). Similar findings have been reported for InA opioid self-administration, including fentanyl (Fragale et al. 2020; Martin et al. 2020; O'Neal et al. 2020). With this procedure, rats had unrestricted, fixedratio 1 , access to rapidly delivered infusions of fentanyl $(\sim 1 \mathrm{~s})$ during 5 -min trials that initiated every $30 \mathrm{~min}$ around the clock. As with the training phase, each trial initiated with the extension of the left lever into the operant chamber and responses on this lever during each trial were reinforced under a fixed-ratio 1 schedule; each infusion was also paired with the sound of the pump and the illumination of the stimulus light above the lever. However, in contrast to training sessions, no priming infusions were administered, and no time-outs were imposed during IntA sessions. The left lever retracted at the end of each trial; responses on the right lever were recorded throughout the 24-h sessions. Sessions continued daily for 10 days. Incidences of self-injurious gnawing were managed using topically applied antibiotic cream and/or systemically administered antibiotic (gentamicin, $5.5 \mathrm{mg} / \mathrm{kg}$, i.v.).

\section{Buprenorphine treatment during abstinence}

Rats were chronically treated with buprenorphine beginning on abstinence day 1 by implanting a subcutaneous minipump containing either buprenorphine ( $3 \mathrm{mg} / \mathrm{kg} /$ day; males $n=20$; females $n=27$ ) or vehicle (ultrapure water; males $n=13$; females $n=17$ ) under isoflurane anesthesia and using methods

\section{Abstinence (14 days) $\longrightarrow$ Relapse (1 day) $\longrightarrow$ Blood}

[Buprenorphine $(3 \mathrm{mg} / \mathrm{kg} /$ day) or Vehicle/Control]

session, rats were implanted with a subcutaneous minipump to deliver either buprenorphine ( $3 \mathrm{mg} / \mathrm{kg}$ /day) or control (vehicle or sham implant). Following a 14-day abstinence period, vulnerability to relapse was assessed in a single session using an extinction/cue-induced reinstatement procedure. The following morning, blood was collected to assess buprenorphine levels in plasma and estradiol/progesterone levels (females) in serum

previously described (Sorge et al. 2005). The daily dose was calculated based on average weights observed in a pilot study of untreated males and females over a 15-day abstinence period and the milligrams per kilogram dose was selected based on findings showing that it offsets heroin-induced increases in nucleus accumbens dopamine (Sorge et al. 2005) and decreases cue-induced heroin-seeking in males (Sorge et al. 2005 ) without producing non-selective effects (Sorge et al. 2005; Bossert et al. 2020). We also included additional control rats who underwent a sham implantation procedure, but without the minipump implantation (males $n=8$; females $n=10$ ), since several previous studies have noted that rats readily tolerate vehicle mini-pumps with evidence indicating no effects on self-administration or seeking behavior (Kunko et al. 1998; Rada et al. 2001; Vann et al. 2006; Sorge and Stewart 2006). These rats also did not differ from vehicle controls on any of the measure examined in the present study; thus, these groups were combined to make one control group ( $n=21$ males; $n=$ 27 females).

Two males were excluded from the study due to patency issues and one male and four females were excluded due to fentanyl toxicity/health issues during IntA self-administration or abstinence. These rats are not included in the total subject numbers and their data were excluded from all analyses. The final group numbers for males and females in the no time-out groups were 10 and 12 for buprenorphine and 11 and 12 for control, respectively; the final group numbers for males and females in the time-out groups were 10 and 15 for buprenorphine and 10 and 15 for control, respectively.

\section{Extinction and reinstatement testing}

Vulnerability to relapse was assessed using an extinction/ reinstatement procedure following protracted abstinence (14 days), as compulsive opioid use and levels of opioidseeking incubate to peak levels within 14 days (Grimm et al. 2001). Extinction responding was examined in a minimum of six, 1-h sessions using methods previously described (Sanchez et al. 2014; Peterson et al. 2014; Beiter et al. 2016). Briefly, sessions began with the introduction of the left lever into the operant chamber and responses on this lever, as well as the right lever, were recorded, but did not have a consequence. Sessions continued until responding 
extinguished ( $\leq 15$ responses/h; typically within six sessions, but up to eight sessions). A 1-h cue-induced reinstatement session began 5 min after the last extinction session with the introduction of the left lever into the operant chamber and a presentation of the cues formerly associated with fentanyl (sound of pump activation and the light above the left lever; $\sim 1 \mathrm{~s})$. Each response on the left lever produced these same cues.

\section{Plasma/serum assays}

Trunk blood was collected the morning following the extinction/reinstatement test (between $10 \mathrm{AM}$ and $12 \mathrm{PM}$ ) and separated into plasma and serum using methods previously described (Lynch 2008, 2009). Plasma buprenorphine concentrations were determined in all of the buprenorphine-treated rats (except for one female due to technical issues with the assay) as well as a subset of the each of the control groups ( $n=4$ /group). Serum concentrations of estradiol and progesterone were determined in all of the female rats (except 1 in the control group due to technical issues), using methods previously described (Lynch 2008). Radioimmunoassays were conducted in duplicate at the University of Virginia Center for Research in Reproduction Ligand Assay and Analysis Core.

\section{Estrous cycle phase determination}

Estrous cycle phase was determined over a 5-day period beginning 3 days prior to extinction/reinstatement testing, in order to habituate them to the procedure, and then continuing until the day after testing so that we could track their cycles leading up to and following relapse testing. Swabs were conducted between 11:30 AM and 12 PM as described previously (Lynch et al. 2019), and estrous cycle phase was determined based on previously published criteria (Feder 1981). In order to determine associations with estrous cycle phase and responding during extinction and reinstatement testing, swabs obtained on the day of extinction/reinstatement test were further categorized as either estrus ( $n=12$ for buprenorphine and $n=11$ for control) or non-estrus ( $n=15$ for buprenorphine and $n=16$ for control); this strategy has been used previously by our group (Peterson et al. 2014; Lynch et al. 2019) and others (Kerstetter et al. 2008) and is based on findings showing that drug-seeking, including opioid-seeking, is higher during estrus as compared to non-estrus phases, and does not differ between metestrus, diestrus, and proestrus phases (Lynch et al. 2019; Lacy et al. 2020).

\section{Drugs}

Fentanyl hydrochloride and buprenorphine hydrochloride were obtained from the National Institute on Drug Abuse
(Research Triangle Park, NC). Fentanyl was dissolved in sterile saline at a concentration of $6.25 \mu \mathrm{g} / \mathrm{mL}$, filtered $(0.22 \mu \mathrm{m}$; Millipore, Billerica, MA), and stored in sterile bottles at $4{ }^{\circ} \mathrm{C}$. The $\mathrm{mg} / \mathrm{kg}$ dose was adjusted for changes in body weight three times a week by adjusting the infusion duration. Buprenorphine was dissolved in ultra-pure water and delivered via a subcutaneous osmotic minipump (Alzet model 2ML4; Durect Corp., Cupertino, CA) at a dose of $3 \mathrm{mg} / \mathrm{kg}$ / day and a mean pumping rate of $2.5 \mu \mathrm{L} / \mathrm{h}$.

\section{Data analysis}

We first determined whether there were sex and time-out training condition effects on rates of acquisition, responding during training, and subsequent intake and patterns of responding during the IntA access period. Acquisition differences were assessed by comparing the number of days to acquire self-administration using two-factor ANOVA with sex and time-out training condition as the between-subject factors. Group differences in responding during training were assessed across the five acquisition criterion sessions using repeated measures ANOVA with separate analysis for active and inactive lever responses. Similar analyses were used to assess sex and time-out training condition differences in total intake across the 10 IntA self-administration sessions and diurnal patterns of intake (average percent of total intake in the dark phase and average intake in light and dark phase) during each of the IntA sessions as well as averaged over the initial (1-2) versus later (sessions 6-10) IntA sessions. We also added treatment condition (buprenorphine versus control) as an additional factor in these analyses in order to ensure that the groups were similar on all measures prior to abstinence and buprenorphine versus control treatment. We also assessed group differences in body weight at the end of the IntA procedure (mean weight observed on days 8-10) in order to confirm that the groups were similar prior to abstinence and treatment using three-factor ANOVA.

For extinction and reinstatement responding, since males and females in each of the time-out training groups received either buprenorphine or control treatment during abstinence, effects were compared between the eight groups (males/females, no time-out/time-out, buprenorphine/control) using repeated measures ANOVA. Specifically, for extinction, responses on the formerly active lever were compared across the first six extinction sessions run, and for reinstatement, responses on the formerly active lever were compared between the last extinction session and the reinstatement session. We also assessed total responding during extinction across all sessions run (6-8) using a three-factor ANOVA (sex, time-out training condition, and treatment group). A similar repeated measures ANOVA was used to assess group differences in mean body weights during early (days 1-3), immediate (days 6-8), and late abstinence (days 12-14), as well as on the day 
of relapse testing (day 15). Similar three-factor ANOVAs were used to assess group differences in plasma levels of buprenorphine, and to assess effects of estrous cycle phase (estrus, non-estrus) on total extinction and reinstatement responding in females. Serum estradiol and progesterone levels in females were analyzed using a two-factor ANOVA (time-out training condition and treatment group). All post hoc comparisons were corrected for multiple comparisons using the Bonferroni method. Statistical analyses were performed using SPSS (V26). Alpha was set at 0.05.

\section{Results}

\section{Fentanyl self-administration training}

\section{Effects of sex and time-out training condition}

All rats met the acquisition criterion fairly rapidly under these moderate to high dose conditions, generally within the first 5-7 days, and no significant effects of sex or time-out training condition were observed $(P$ 's $>0.05$; Fig. 2a). However, significant effects of sex and timeout training condition were observed for levels of active and inactive lever responding during the five acquisition criterion sessions (Fig. 2b,c). For active lever responses, there was a significant effect of sex $\left(F_{1,91}=6.88, P=\right.$ $0.01)$ and time-out training condition $\left(F_{1,91}=25.49\right.$, $P<0.01$ ), with males responding at higher levels than females and with males and females in the time-out group responding more than those in the no time-out group (Fig. 2b). We also observed non-significant overall and interactive effects of day $(P$ 's $>0.05)$ indicating that these differences were similar across the 5 criterion sessions. For inactive lever responses, there was a significant effect of day $\left(F_{4,364}=2.45, P<0.05\right)$ and day by training group $\left(F_{4,364}=3.63, P<0.01\right)$, with rats in the no time-out group responding at higher levels than rats in the time-out group, particularly during the later acquisition criterion sessions (Fig. 2c). Further analysis of inactive lever responding within days 1 to 3 and 4 to 5 revealed a significant effect of training group for days 4 to 5 only $\left(F_{1,91}=6.19, P<0.05\right)$. Thus, while time-out training condition did not impact the speed of acquisition, the inclusion of a time-out resulted in increased active lever responding, and decreased inactive lever responding. Males trained with and without a time-out also responded at higher levels on the active lever than their female counterparts.

\section{No differences between the treatment groups}

Rats that were later given buprenorphine versus control treatment during abstinence acquired fentanyl selfadministration at similar rates (Table 1) with results from the three-factor ANOVA comparing the number of days to acquire self-administration revealing nonsignificant overall and interactive effects of treatment group $(P$ 's $>0.05)$. There were also no differences in active and inactive lever responses during the five acquisition criterion sessions between rats later given buprenorphine versus control treatment during abstinence. Thus, rats given buprenorphine versus control a

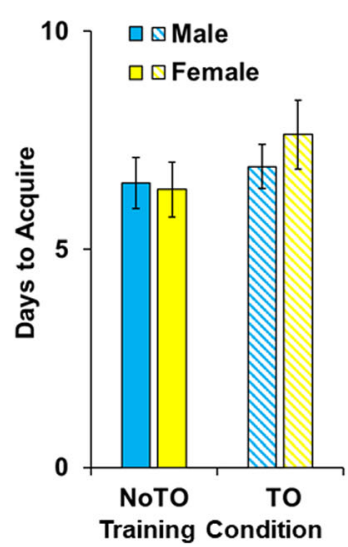

b

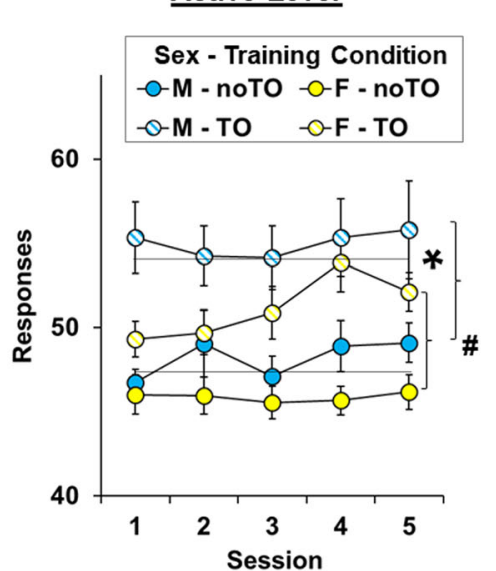

C

Inactive Lever

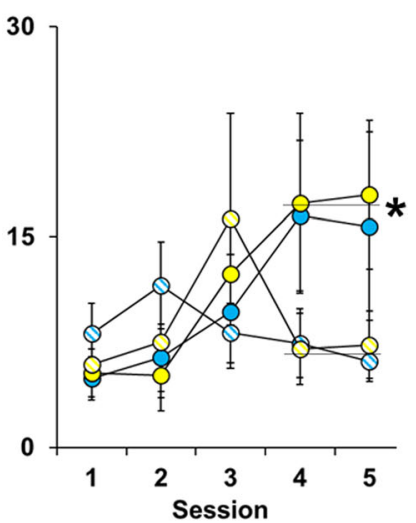

Fig. 2 Effect of sex and timeout training condition on rates of acquisition and active and inactive lever responding during the 5-day acquisition criterion period. Mean $( \pm \mathrm{SEM})$ number of days to acquire fentanyl self-administration (a) and the mean $( \pm$ SEM) number of active (b) and inactive (c) lever responses for each of the five acquisition criterion sessions for males $(\mathrm{M})$ and females $(\mathrm{F})$ in the no time-out (noTO, $n=$ 21 and 24 , respectively) and time-out (TO, $n=20$ and 30 , respectively) training conditions. *Significant effect of time-out training condition over the 5 acquisition sessions (b) and during the last 2 sessions (c); \#Significant effect of sex over the 5 sessions (b) 
Table 1 Male and female rats in the no time-out and time-out training groups that were later given buprenorphine or control treatment during abstinence acquired self-administration in a similar number of days, obtained similar amounts of fentanyl over the 10-day intermittent access period, and weighed a similar amount prior to abstinence and treatment (last body weight during the intermittent access period)

\begin{tabular}{llllll}
\hline Sex & $\begin{array}{l}\text { Time-out } \\
\text { group }\end{array}$ & $\begin{array}{l}\text { Treatment } \\
\text { group }\end{array}$ & Days to acquire & $\begin{array}{l}\text { Daily intake } \\
(\mu \mathrm{g} / \mathrm{kg})\end{array}$ & $\begin{array}{l}\text { Body weight } \\
(\mathrm{g}) *\end{array}$ \\
\hline Males & No time-out & Control & $6.4 \pm 0.6$ & $61.9 \pm 7.2$ & $455 \pm 9$ \\
& & Buprenorphine & $6.7 \pm 1.1$ & $58.9 \pm 11.7$ & $471 \pm 12$ \\
& Time-out & Control & $7.2 \pm 0.9$ & $63.5 \pm 12.1$ & $474 \pm 14$ \\
& & Buprenorphine & $6.6 \pm 0.5$ & $60.8 \pm 9.4$ & $468 \pm 15$ \\
Females & No time-out & Control & $6.3 \pm 1.1$ & $93.5 \pm 12.6$ & $308 \pm 4$ \\
& & Buprenorphine & $6.5 \pm 0.7$ & $93.3 \pm 9.3$ & $332 \pm 6$ \\
& \multirow{2}{*}{ Time-out } & Control & $8.7 \pm 1.4$ & $55.7 \pm 6.8$ & $309 \pm 7$ \\
& & Buprenorphine & $6.6 \pm 0.8$ & $73.3 \pm 8.1$ & $302 \pm 3$ \\
\hline
\end{tabular}

Data are presented as mean \pm SEM

*Significant difference between males and females treatment had similar rates and patterns of responding during acquisition.

\section{IntA self-administration}

\section{Effects of sex and time-out training condition}

Females in the no time-out training group self-administered more fentanyl than all other groups with results from the repeated measures ANOVA revealing an interaction of sex and training group $\left(F_{1,91}=5.05, P<0.05\right.$; Fig. 3$)$; post hoc comparisons to females in the no-time-out group were also significant for each of the groups $(P$ 's $<0.05)$. We also observed significant overall effects of sex $\left(F_{1,91}=6.74, P<0.05\right)$ and time-out training group $\left(F_{1,91}=4.02, P<0.05\right)$, but each of

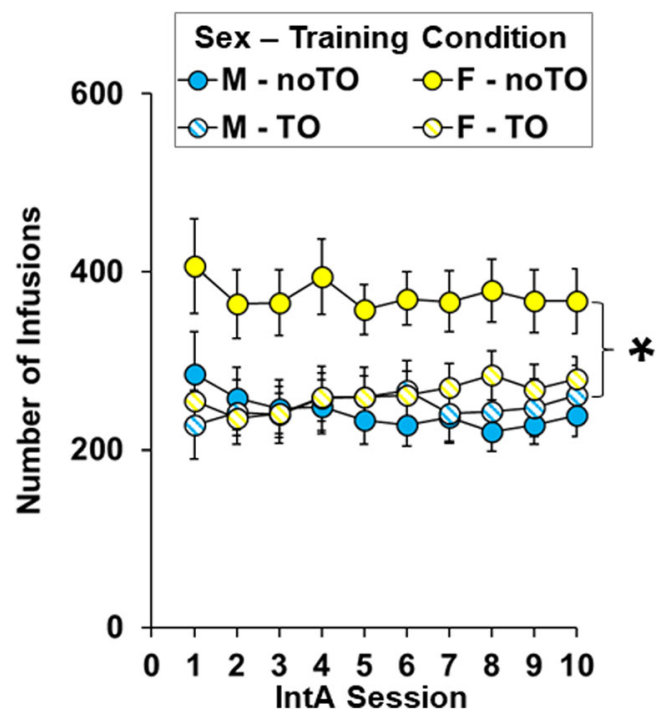

Fig. 3 Effect of sex and time-out training condition on subsequent fentanyl intake under extended, intermittent access conditions. Mean $( \pm \mathrm{SEM})$ number of fentanyl infusions obtained during each of the 10 intermittent access sessions for males (M) and females (F) in the no time-out (noTO, $n=21$ and 24, respectively) and time-out (TO, $n=20$ and 30, respectively) training groups. * Significant difference between females in the noTO group and all other groups these effects appear to be driven by females in the no timeout training group given that intake was equivalent between the other three groups $(P$ 's $>0.05)$. Thus, females trained to self-administer fentanyl without a time-out after each infusion showed greater subsequent intake of fentanyl under extended IntA conditions compared to females trained with a time-out and to males trained with or without a time-out.

While patterns of fentanyl intake did not differ between rats trained with and without a time-out, we observed changes in daily patterns of intake over time (Fig. 4a; effect of day, $\left.F_{9,783}=26.25, P<0.001\right)$ as well as sex differences in these changes (day by sex, $F_{9,783}=3.69, P<0.001$ ). Specifically, during the initial IntA sessions (sessions 1-2), both males and females self-administered significantly more fentanyl during the dark versus light phase of the light-dark cycle $(P<0.05)$. There was no difference between males and females for the percent of the total intake in the dark phase averaged over these initial sessions $(58 \pm 2 \%$ and $55 \pm 2 \%$, respectively; $P>0.05$ ). However, beginning around session 3 , the diurnal control over intake was lost (equal intake in the dark versus light; $P>0.05$ ). Patterns of intake stabilized around day 6 , and for sessions $6-10$, both males and females took fewer fentanyl infusion in the dark versus light phase $(P<0.05)$; males also took significantly less of their total fentanyl in the dark phase than females $(41 \pm 1 \%$ and $45 \pm 1 \%$, respectively; $P<0.01$ ).

To further explore sex differences in daily patterns of fentanyl self-administration over time, we plotted hourly intake of fentanyl averaged across the initial (sessions 1-2; Fig. 4b) versus the latter sessions (sessions 6-10; Fig. 4c). During the initial sessions, hourly patterns of intake showed that rats selfadministered significantly more fentanyl in the dark versus late phase (effect of phase, $F_{1,93}=25.48, P<0.001$ ); there was no overall or interactive effects of sex $(P$ 's $>0.05)$. Also consistent with the percent dark phase analysis, the analysis of light versus dark phase fentanyl intake averaged across the latter sessions (sessions 6-10) showed that rats selfadministered significantly more fentanyl in the light versus 


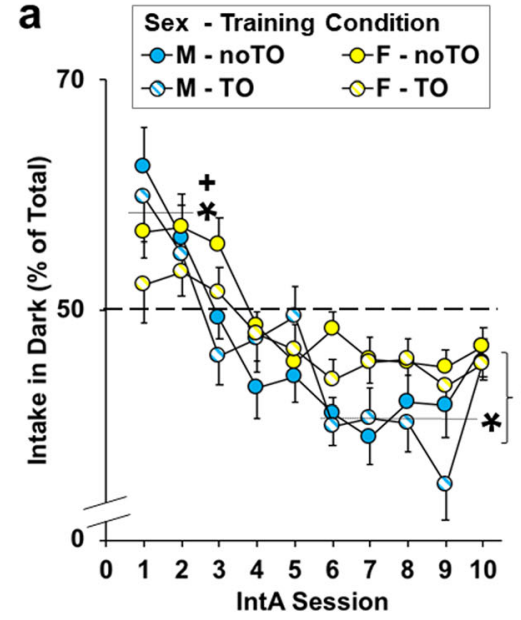

Fig. 4 Effects of sex and time-out training condition on patterns of fentanyl self-administration under extended, intermittent access conditions. (a) Mean $( \pm$ SEM) percent of total fentanyl intake that occurred in the dark phase for each of the 10 intermittent access sessions and the mean $( \pm$ SEM) number of fentanyl infusions obtained during each hour of access averaged access sessions 1-2 (b) and 6-10 (c) of the intermittent access period for males $(\mathrm{M})$ and females $(\mathrm{F})$ in the no time-out (noTO, $n=21$

dark phase (effect of phase, $F_{1,93}=57.43, P<0.001$ ). There was also a significant overall sex effect $\left(F_{1,93}=6.36, P<0.05\right)$ and phase by sex interaction $\left(F_{1,93}=4.49, P<0.05\right)$ with males self-administering similar levels of fentanyl in the light phase $(P>0.05)$, but less fentanyl in the dark phase $(P=$ 0.001) compared to females. Thus, during the 10-day IntA period, fentanyl self-administration transitioned from being phase-locked to the dark phase to having no apparent daily rhythm, and with males obtaining less fentanyl during the dark phase as compared to females.

Despite these differences in patterns and levels of intake, no overall or interactive effects of time-out training condition were observed for body weight at the end of the IntA selfadministration period ( $P$ 's $>0.05$; Table 1$)$. There was, however, a marked sex difference $\left(F_{1,87}=638.69, P<0.001\right)$ with males weighing more than females.

\section{Buprenorphine treatment during abstinence}

Rats later receiving buprenorphine versus control treatment during abstinence self-administered similar levels of fentanyl (see Table 1) and showed a similar diurnal pattern of intake over the 10-day IntA period. Results from the three-factor ANOVA comparing average intake and average percent intake in the dark across the 10 IntA sessions revealed nonsignificant overall and interactive effects of treatment group $(P$ 's $>0.05)$. Thus, rats in the buprenorphine versus control groups had a similar history of fentanyl self-administration prior to abstinence and treatment. Rats in these groups also weighed a similar amount at the end of the IntA selfadministration period (see Table 1) and no significant overall
C Sessions 6-10

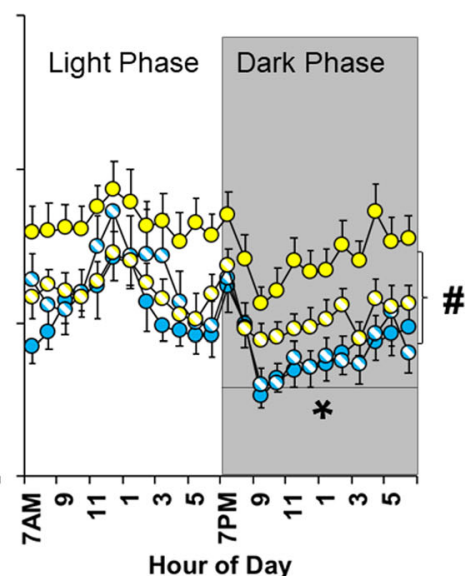

and 24 , respectively) and time-out (TO, $n=20$ and 30, respectively) training groups. *Significant effect of light-dark phase: greater fentanyl intake in the dark versus light for sessions 1 and $2(\mathbf{a}, \mathbf{b})$ and lower intake in the dark versus light for sessions 6-10 (a, c). +Significant decrease in average percent intake in the dark phase from sessions $1-2$ versus 6-10 (a). \#Significantly lower fentanyl intake in males compared to the females in the dark phase for sessions 6-10 (a, c)

or interactive effects of treatment group on body weight were observed ( $P$ 's $>0.05)$.

\section{Extinction and reinstatement testing}

\section{Effects of sex, time-out training condition, and buprenorphine treatment}

Extinction responding over the first six extinction sessions was higher in females than males (effect of sex, $F_{1,87}=4.73$, $P<0.05$; Fig. 5a, b), and highest in all groups during the first session versus later ones (effect of session, $F_{5,435}=60.07$, $P<0.001$; session 1 versus $2,3,4,5$, and $6, P$ 's $<0.001$ ). Although extinction responding appeared to be elevated in females in the no time-out training group, this effect was variable, only apparent within the controls, and none of the overall or interactive effects of time-out training condition were significant $(P$ 's $>0.05)$. As predicted, buprenorphine treatment during abstinence decreased extinction responding (effect of treatment, $F_{1,87}=21.43, P<0.001$ ), particularly during the initial extinction sessions when responding was high (interaction of session by treatment, $F_{5,435}=16.77, P<0.001$ ). Further analysis within each session revealed significant effects of treatment within extinction sessions 1,2 , and 3 ( $P$ 's $<$ 0.001 ). We also observed non-significant interactions of sex by treatment and sex by treatment by session indicating that buprenorphine similarly decreased responding in males and females. Similar effects were observed for total extinction responses across all extinction sessions run (Fig. 5c, d) with results from the univariant analysis revealing significant overall effects of $\operatorname{sex}\left(F_{1,87}=4.19, P<0.05\right)$ and treatment 

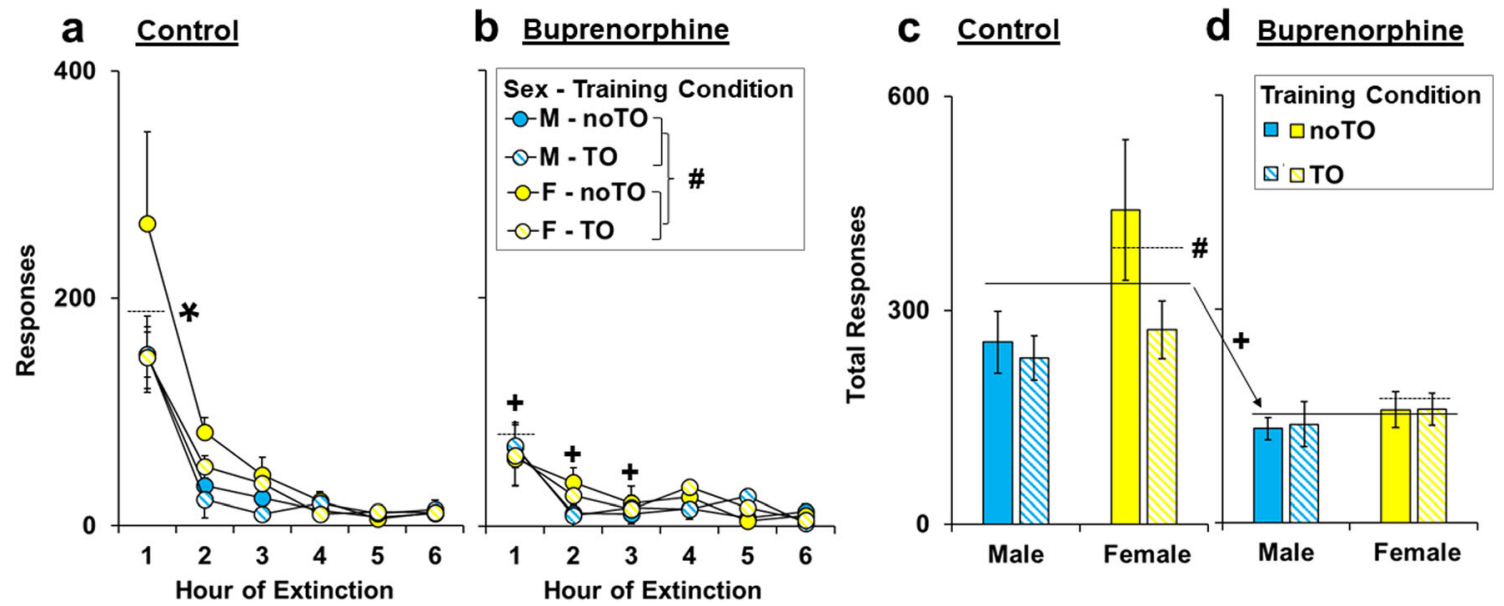

Fig. 5 Effect of sex, time-out training condition, and buprenorphine treatment on fentanyl-seeking during extinction testing. Mean ( \pm SEM) number of responses made on the lever formerly associated with fentanyl during the first six 1-h extinction sessions $(\mathbf{a}, \mathbf{b})$ and across all extinction sessions run $(\mathbf{c}, \mathbf{d})$ for control treated $(\mathbf{a}, \mathbf{c})$ male $(\mathrm{M})$ and female $(\mathrm{F})$ rats in the no time-out (noTO, $n=11$ and 12 , respectively) and time-out (TO, $n=10$ and 15 , respectively) training groups and for buprenorphine-

treated $(\mathbf{b}, \mathbf{d})$ male and female rats in the no time-out $(n=10$ and 12 , respectively) and time-out ( $n=10$ and 15 , respectively) training groups. *Significantly higher responses during the first extinction session versus later ones (2-6) across the control and buprenorphine groups (a). \#Significant overall effect of sex $(\mathbf{a}-\mathrm{d})$. + Significant overall effect of buprenorphine (c, d) and within the first 3 sessions $(\mathbf{a}, \mathbf{b})$

$\left(F_{1,87}=21.57, P<0.001\right)$, a non-significant interaction of sex by treatment $(P>0.05)$, and non-significant overall and interactive effects of training group ( $P$ 's $>0.05$ ).

In contrast to effects during extinction, males and females responded at similar levels during reinstatement testing (Fig. 6a, b) with results from the repeated measures ANOVA comparing responding during the last extinction session to the reinstatement session revealing non-significant overall and interactive effects of sex ( $P^{\prime}$ s $\left.>0.05\right)$. As with extinction responding, however, buprenorphine treatment decreased responding during reinstatement with results revealing a significant effect of treatment $\left(F_{1,87}=13.21, P<0.001\right)$, session $\left(F_{1,87}=38.21, P<0.001\right)$, and session by treatment $\left(F_{1,87}=13.92, P<0.001\right)$. Although no group difference was observed within the last extinction session $(P>0.05)$, there was a significant difference between the buprenorphine and

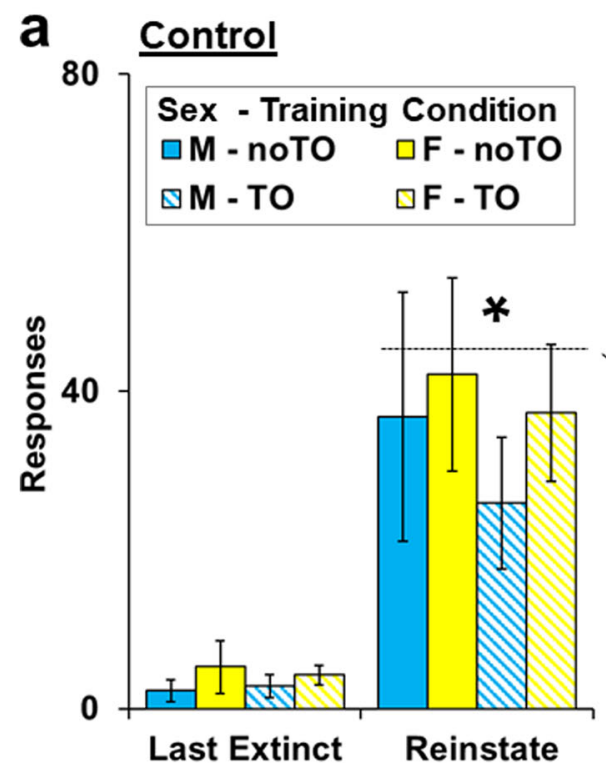

\section{b Buprenorphine}

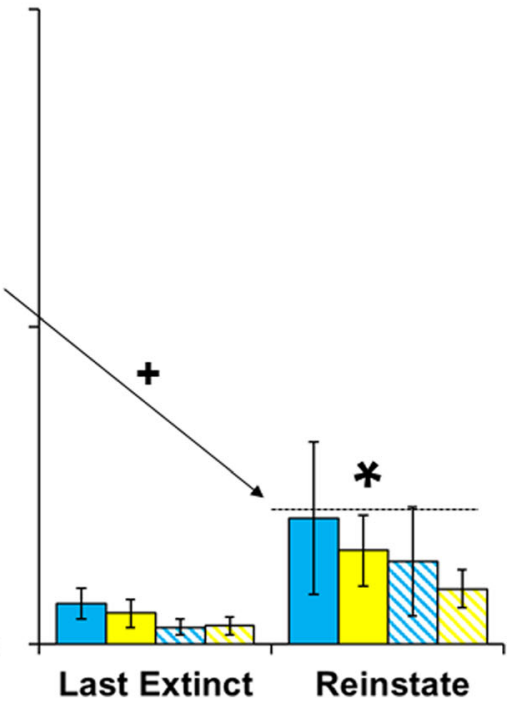

Fig. 6 Effect of sex, time-out training condition, and buprenorphine treatment on fentanyl-seeking during cue-induced reinstatement testing. Mean $( \pm$ SEM) number of responses made on the lever formerly associated with fentanyl during the last extinction session versus the reinstatement session for control treated (a) male $(\mathrm{M})$ and female $(\mathrm{F})$ rats in the no time-out (noTO, $n=11$ and 12, respectively) and time-out (TO, $n=10$ and 15,

respectively) training groups and for buprenorphine-treated (b) male and female rats in the no time-out ( $n=10$ and 12, respectively) and time-out ( $n=10$ and 15 , respectively) training groups. *Significant difference from the last extinction session $(\mathbf{a}, \mathbf{b})$. +Significant effect of buprenorphine $(\mathbf{a}, \mathbf{b})$ 
control group within the reinstatement session $(P<0.001)$. Further analysis within each of the groups revealed a significant effect of session within both the control $(P<0.001)$ and buprenorphine groups $(P<0.01)$, indicating that while buprenorphine decreased responding during reinstatement testing, it did not prevent the reinstatement of responding following extinction in response to fentanyl-associated cues. As with extinction responding, time-out training condition did not significantly impact responding during reinstatement and all overall and interactive effects of time-out condition were non-significant.

Thus, females had higher levels of drug-seeking than males (during extinction); buprenorphine decreased drug-seeking in both males and females and eliminated sex differences in drug-seeking. In contrast to effects observed on intake during the IntA component of the study, rats trained with and without a time-out during acquisition responded at similar levels during extinction and reinstatement and showed a similar response to buprenorphine treatment.

\section{Body weight}

\section{Effects of sex, time-out training condition, and buprenorphine treatment}

Although no significant effects of training condition were observed for body weight, as with effects observed at the end of the IntA self-administration period, marked sex differences were observed during each of the abstinence/treatment and relapse testing time-points (Fig. 7; overall effect of sex, $F_{1,87}=764.75, P<0.001$; within each time-point, $P$ 's $<$ $0.001)$. We also observed significant effects of time $\left(F_{3,261}=63.41, P<0.001\right)$, time by treatment group $\left(F_{3,261}=54.32, P<0.001\right)$, time by sex $\left(F_{3,261}=9.42\right.$, $P<0.001)$, and time by treatment group by sex $\left(F_{3,261}=\right.$ $6.46, P<0.001)$. Further analysis within the control and buprenorphine groups revealed a significant effect of time within the control group $(P<0.05)$, but not within the buprenorphine group $(P>0.05)$ indicating that buprenorphine prevented weight gain over time. Similar findings of a significant effect of session within the control group, but not the buprenorphine group, were also observed in separate analyses within males and females ( $P$ 's $>0.05)$. These analyses also revealed a significant interaction of treatment by time within males $\left(F_{3,117}=27.41, P<0.001\right)$ and females $\left(F_{3,156}=24.10\right.$, $P<0.001)$; however, the post hoc comparisons of body weights were not significant at any of the time-points within females ( $P$ 's $>0.05)$, but within males, there was a difference on the relapse test session $(P<0.01)$ and a trend for a difference on abstinence day $14(P=0.064)$. These results indicate that buprenorphine prevented weight gain over abstinence, particularly in males.

\section{Associations with plasma and serum}

As expected, buprenorphine-treated rats had significantly higher levels of buprenorphine in plasma as compared to the negligible levels observed in control rats $(21.5 \pm 2.1 \mathrm{ng} / \mathrm{mL}$ and $0.4 \pm 0.4 \mathrm{ng} / \mathrm{mL}$, respectively; $t_{61}=5.83, P<0.001$ ). Levels were also similar between each of the buprenorphinetreated groups (effects of time-out condition, $P$ 's $>0.05$ ), although there was a tendency for females to have higher plasma buprenorphine levels than males $(24.6 \pm 2.8 \mathrm{ng} / \mathrm{mL}$ and $17.28 \pm 3.2 \mathrm{ng} / \mathrm{mL}$, respectively; $F_{1,43}=2.98, P=0.091$ ). Serum estradiol levels were similar between female rats in the control and buprenorphine groups $(4.7 \pm 0.4 \mathrm{pg} / \mathrm{mL}$ and $5.69 \pm 0.68 \mathrm{pg} / \mathrm{mL}$, respectively), and all overall or interactive effects of treatment and time-out training condition were nonsignificant $(P>0.05)$. While serum progesterone levels also did not differ significantly between the time-out training groups $(P$ 's $>0.05)$, there was a non-significant trend for higher levels of serum progesterone in controls as compared to buprenorphine-treated rats $(28.7 \pm 4.0 \mathrm{ng} / \mathrm{mL}$ versus $19.6 \pm$ $3.0 \mathrm{ng} / \mathrm{mL}$; effect of treatment, $\left.F_{1,48}=3.12, P=0.084\right)$. No significant group differences were observed for the ratio of estradiol to progesterone in serum ( $P$ 's $>0.05)$. These results confirm the presence of buprenorphine following relapse testing and show that such treatment did not impact estradiol, and only modestly (and non-significantly) impacted progesterone.

\section{Effect of estrous cycle phase}

As shown in Fig. 8, buprenorphine treatment decreased extinction (a) and reinstatement (b) responding in females tested during both estrus and non-estrus phases. Since no significant effects of time-out training condition were observed for extinction or reinstatement responding in the previous analyses, or in this analyses of estrus and non-estrus females $(P$ 's $>$ 0.05 ), the data presented here are collapsed across time-out training condition. For extinction, there was a significant overall effect of treatment $\left(F_{1,50}=16.12, P<0.001\right)$ and estrus cycle phase $\left(F_{1,50}=4.06, P<0.05\right)$, and a non-significant trend for an interaction between treatment and estrous cycle phase $(P=0.076)$ indicating that levels of extinction responding were higher in estrus versus non-estrus females and decreased in both estrus and non-estrus females by buprenorphine treatment. For reinstatement, there was a significant overall effect of treatment $\left(F_{1,50}=24.37, P<0.001\right)$, as well a significant overall effect of phase $\left(F_{1,50}=4.58\right.$, $P<0.05)$ and an interaction of phase by treatment $\left(F_{1,44}=\right.$ 5.14, $P<0.05)$. Further analysis within each of the treatment groups revealed a significant effect of phase within the control group $(P<0.05)$ but not the buprenorphine group $(P>0.05)$, indicating that the overall effect of phase was driven by the heightened responding in estrus female in the control group. Post hoc comparison of each of the control groups to the 


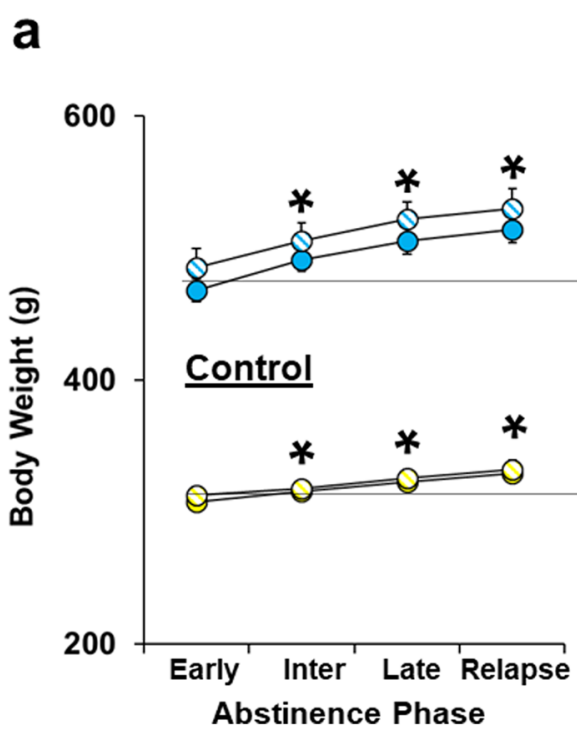

b

Sex - Training Condition

-OM - noto -O-F - noto

$-Q-M-T O \quad-O-F-T O$

Abstinence Phase

Fig. 7 Effect of sex, time-out training condition, and buprenorphine treatment on body weight $(\mathrm{g})$ during the abstinence/treatment and relapse testing phases of the study. Mean ( \pm SEM) body weight ( $g$ ) during early (Early, days 1-3), intermediate (Inter, days 6-8), and late (Late, days 1214) abstinence as well as on the day of the relapse test (Relapse) for control treated (a) male $(\mathrm{M})$ and female $(\mathrm{F})$ rats in the no time-out (noTO, $n=11$ and 12, respectively) and time-out (noTO, $n=10$ and 15,

buprenorphine group (collapsed across estrous cycle phase) revealed significant differences for both estrus $(P<0.001)$ and non-estrus females $(P<0.01)$; however, the effect size, as measured using partial eta-squared, was robust for the estrus-control versus buprenorphine comparison (0.47) versus medium-to-large for the non-estrus-control versus buprenorphine comparison (0.21). These findings are also
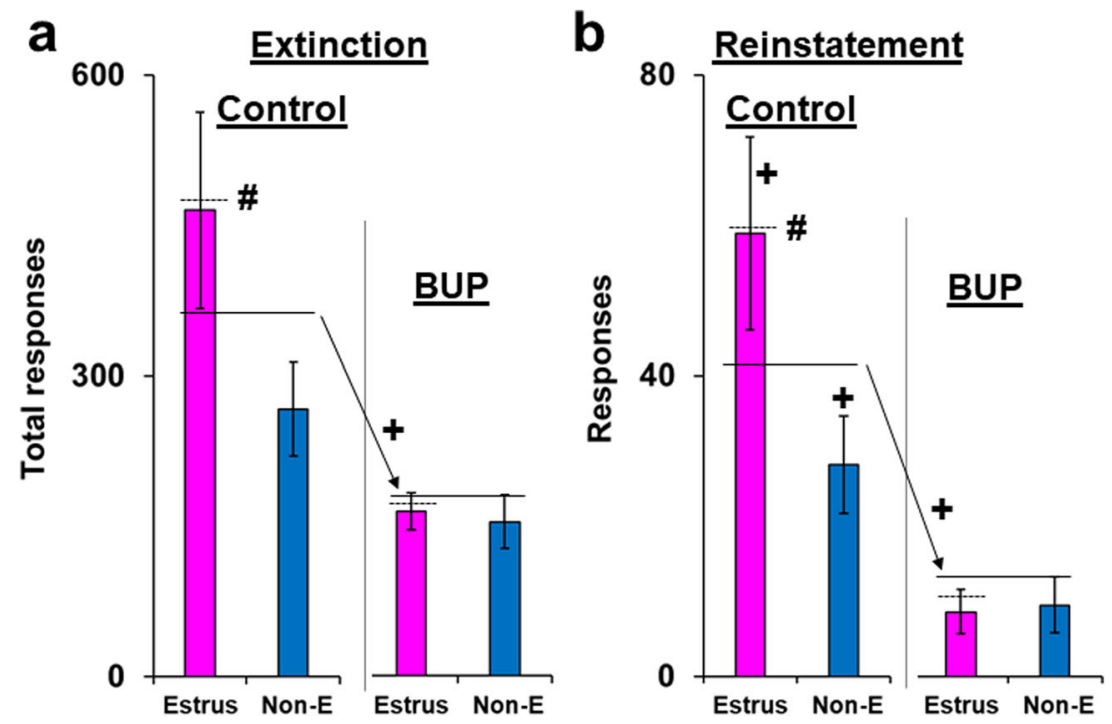

Fig. 8 Effect of estrous cycle phase and buprenorphine treatment on fentanyl-seeking during extinction and reinstatement testing. a Mean total $( \pm$ SEM) responses made on the lever formerly associated with fentanyl across all extinction sessions run (6-8) and $\mathbf{b}$ during the reinstatement test session for control (left panels) and buprenorphine-treated (BUP; right panels) females tested during estrus (Estrus; $n=11$ and 12, respectively)

consistent with the significant interaction of phase by treatment and indicate that buprenorphine treatment had a larger impact in females tested during estrus versus non-estrus phases. Thus, buprenorphine decreased fentanyl-seeking during both extinction and reinstatement testing and was particularly effective at decreasing estrus-heightened reinstatement responding.

respectively) training groups and for buprenorphine-treated (b) male and female rats in the no time-out ( $n=10$ and 12 , respectively) and time-out ( $n=10$ and 15, respectively) training groups. \#Significant effect of sex overall and at each of the time-points during abstinence/treatment and relapse testing $(\mathbf{a}, \mathbf{b})$. * Significant difference from Early (a). + Significant effect of buprenorphine $(\mathbf{a}, \mathbf{b})$

versus non-estrus (Non-E; $n=16$ and 15 , respectively) phases. \#Significant overall effect of estrous cycle phase (a, b). +Significant overall effect of buprenorphine (a, b) and for both control estrus and non-estrus rats as compared to buprenorphine rats (collapsed across estrous cycle phase; $\mathbf{b}$ ) 


\section{Discussion}

Fentanyl self-administration under these extended IntA conditions induced high levels of subsequent fentanyl-seeking during extinction and reinstatement testing, which were greatly attenuated by buprenorphine treatment during abstinence. Consistent with our hypothesis, females self-administered more fentanyl and had higher levels of drug-seeking during subsequent extinction testing as compared to males. Despite this enhanced vulnerability in females, buprenorphine was at least as effective at decreasing fentanyl-seeking in females versus males. In fact, the efficacy of buprenorphine was most pronounced in females tested during estrus, when levels of drug-seeking were the highest. These findings demonstrate the utility of this model for determining sex and hormonal influences on the efficacy of treatments for OUD. Interestingly, the inclusion of a time-out during training had a major impact on subsequent fentanyl intake under extended access conditions in females, but not males, underscoring the importance of the initial exposure conditions on later vulnerability to fentanyl in females.

The experimental conditions used in the present study were designed to be optimal for inducing an addiction-like phenotype. Specifically, our extended IntA fentanyl selfadministration procedure was developed based on findings with psychostimulants showing that it induces bingeabstinent patterns of drug intake and marked increases in subsequent drug-seeking and motivation to obtain the drug following protracted abstinence (i.e., Zimmer et al. 2012). Similar findings have also been reported in recent work with opioids (Fragale et al. 2020; Martin et al. 2020; O'Neal et al. 2020). Although fentanyl intake did not escalate over time under these conditions, as with findings with stimulants (Zimmer et al. 2012), fentanyl was self-administered in binge-abstinence patterns that were dysregulated from a normal diurnal cycle (e.g., intake was higher in the light phase). We also assessed vulnerability to relapse following protracted abstinence, when levels of drug-seeking are known to be high and included a test of validity for our relapse model using the anti-craving medication, buprenorphine. As with recent findings in males with opioids (Fragale et al. 2020; Martin et al. 2020; O'Neal et al. 2020 ) and previous findings with stimulants (Zimmer et al. 2012; Calipari et al. 2013, 2014, 2015; Calipari and Jones 2014; Kawa et al. 2016, 2019; Allain et al. 2017, 2018; Singer et al. 2017; Venniro et al. 2018; Kawa and Robinson 2019; Gueye et al. 2019; Nicolas et al. 2019; Allain and Samaha 2019), both males and females responded at high levels during extinction and reinstatement testing following IntA fentanyl self-administration and abstinence. Our findings showing that buprenorphine treatment during abstinence greatly attenuated subsequent fentanyl-seeking provide support for the translational value of our rat model and suggest that it could be useful for screening new potential treatments for OUD.
As predicted, females self-administered more fentanyl than males under extended access conditions and showed a higher subsequent level of drug-seeking following protracted abstinence. These findings are consistent with findings showing that women with an OUD are more motivated to obtain opioids (e.g., greater drug and sexual risk behaviors; Meade et al. 2010), show a faster time-course to the development of an OUD (Hernandez-Avila et al. 2004), and have higher levels of craving during abstinence as compared to men with an OUD (Back et al. 2011a; Kennedy et al. 2013; Moran et al. 2018; Yu et al. 2007). They are also consistent with previous preclinical findings showing that females self-administer more heroin and oxycodone under extended access conditions than males (Carroll et al. 2002; Towers et al. 2019; Kimbrough et al. 2020) and with previous findings with other drugs of abuse showing that females have higher levels of drugseeking than males following extended access selfadministration and abstinence (Lynch 2018). Our current findings showing that sex differences were apparent in some conditions, but not others, may also explain some discrepancies in the occurrence of sex differences under extended access conditions (e.g., Carroll et al. 2002; Towers et al. 2019; Kimbrough et al. 2020; Reiner et al. 2020; Fredriksson et al. 2020; Venniro et al. 2017, 2019) since differences are likely to depend on both the training and extended access conditions. As with the current findings, these previous reports of sex differences in drug-seeking have typically revealed effects during extinction, but not following exposure to drugassociated cues (Lynch 2018). Parallel findings have also been reported in human laboratory studies among individuals with an OUD with women reporting higher baseline levels of craving than men during abstinence (Back et al. 2011a; Kennedy et al. 2013), but similar craving in response to opioidassociated cues (Moran et al. 2018). These findings establish sex as a factor impacting the expression of an opioid addiction-like phenotype and indicate that biological factors contribute to the enhanced vulnerability observed in women.

Interestingly, the conditions used during fentanyl selfadministration training impacted responding during training as well as later self-administration sessions; these conditions also greatly impacted the later occurrence of sex differences. During training, both male and female rats trained with a timeout after each infusion responded at higher levels on the active lever during the five criterion training sessions and at lower levels on the inactive lever during the final two training sessions as compared to male and female rats trained without a time-out. Although males also responded at higher levels on the active lever than females, the effect of time-out training condition on responding during training was similar between the sexes. In contrast, the effect of time-out training condition on later intake under IntA conditions was markedly different between males and females with females trained without a time-out taking considerably more fentanyl than females 
trained with a time-out; no difference was observed within males. It is not clear why the inclusion of a short time-out during training had such a large impact on later intake in females, but not males, especially considering that the inclusion of a time-out similarly impacted responding in males and females during training. A clue into a potential explanation is provided by findings from Calipari and colleagues (Calipari et al. 2017; Johnson et al. 2019; Brady et al. 2019) indicating that in females, the effects experienced during initial drug exposure can have a lasting impact on later selfadministration and drug reward-related behaviors. Specifically, Calipari and colleagues showed in a series of studies that females have a heightened sensitivity to the reinforcing effects of cocaine during estrus, and if they are initially exposed to cocaine during estrus, they continue to have a heightened sensitivity to cocaine even when tested during non-estrus phases of their cycle (Calipari et al. 2017; Johnson et al. 2019; Brady et al. 2019). Thus, one possible explanation for our current findings is that the reinforcing effects of fentanyl were greater for females trained without a time-out as compared to males and females trained with a time-out, which then caused them to have an increased vulnerability to fentanyl during extended access self-administration. One caveat to this idea, however, is that all groups acquired self-administration rapidly and no significant differences were observed for rates of acquisition. Each of the groups also regulated their intake of fentanyl similarly during the training phase (i.e., similar inter-infusion intervals; data not shown). Further research will be necessary to determine why a time-out during training impacted later fentanyl intake in females, but not males.

While the explanation for the effect of time-out training condition on subsequent responding for fentanyl is not clear, the findings are advantageous since they reveal conditions that are ideal for inducing sex differences (without a time-out during training) as well as those that induce equivalent fentanyl self-administration (with a time-out during training). It is notable that even when intake was similar between males and females in the current study (i.e., within the time-out training group), females showed higher subsequent fentanyl-seeking than males. There were also no differences in intake between females who underwent relapse testing during estrus versus non-estrus phases of their cycle, yet fentanyl-seeking was markedly higher in estrus versus non-estrus females. Thus, these procedures appear to be ideally suited for examining sex and hormonal influences on the expression of an opioid addiction-like phenotype under intake equated conditions and female-heightened conditions.

We also observed time- and sex-dependent differences in patterns of intake under these extended access conditions. While several previous studies have also shown that daily patterns are disrupted under extended access selfadministration conditions (Roberts et al. 2002; Lynch and
Taylor 2004; Chen et al. 2006; O'Dell et al. 2007; Bass et al. 2010; Logan et al. 2014), only one previous study examined sex differences (Lynch and Taylor 2004). As with the current findings, this previous study showed that males and females given extended access to cocaine under a discrete trial procedure had a similar dark-phase locked pattern of intake during the initial 1-2 sessions, but a different pattern thereafter (Lynch and Taylor 2004). However, one major difference between the previous findings with cocaine and the findings here with fentanyl is that in the previous study, by the end of the extended access testing period (7 days), dark-phase control over intake was regained in males, and only females remained dysregulated. Here, the phase-dark control over intake was lost in both sexes and males showed even less intake in the dark versus light phase as compared to females. While it is not clear if these differences are due to the drug or extended access conditions, it is notable that sleep dysregulation is reported in both men and women with an OUD (Hartwell et al. 2014; Gordon 2019). Further research is needed to address these discrepancies. Further research is also needed to understand the sex difference observed during the latter sessions, since while it is clear that diurnal control over fentanyl intake was lost in both sexes, the meaning of our finding showing that males self-administered less fentanyl in the dark versus light phase than females during is unclear.

We predicted that buprenorphine would effectively decrease fentanyl-seeking in both sexes given findings in humans showing that it improves treatment retention and reduces opioid use in both women and men with an OUD (Herget 2005; Mattick et al. 2014). However, because the clinical findings have been mixed regarding the potential for buprenorphine to have differential efficacy as an anti-relapse intervention in men versus women (Koons et al. 2018; Huhn et al. 2019), we did not have a prior prediction for sex differences in the efficacy of buprenorphine to reduce fentanylseeking. While our findings showing that buprenorphine markedly reduced fentanyl-seeking in both sexes support this hypothesis, we also have some evidence to suggest that its efficacy may be enhanced in females versus males given that buprenorphine was able to eliminate sex differences in drugseeking, bringing females down to a male level. This was particularly evident in females tested during estrus versus non-estrus phases wherein buprenorphine was able to block the estrus-induced increase in drug-seeking. This idea is also consistent with recent findings showing that in females, buprenorphine decreased extinction and context-induced reinstatement of opioid-seeking, whereas in males, it decreased extinction but did not significantly impact context-induced reinstatement (Bossert et al. 2020).

They are also consistent with previous findings showing that sex differences in regional glucose metabolism during morphine withdrawal were abolished following buprenorphine treatment (Santoro et al. 2017). Several clinical 
studies have also shown that despite greater medical comorbidities and higher levels of craving in women than men at intake, women have at least similar treatment outcomes following buprenorphine treatment (Marsh and Simpson 1986; Rutherford et al. 1997; Schottenfeld et al. 1998; Jones et al. 2005; Jimenez-Treviño et al. 2011; Grella and Lovinger 2012; McHugh et al. 2013; Levine et al. 2015; Öhlin et al. 2015; Palis et al. 2017; Adelson et al. 2018 but see Back et al. 2011a, 2011b; Chopra et al. 2008; Johnson et al. 1995; Marchand et al. 2015; Pérez de los Cobos et al. 2007; Zielinski et al. 2017). Together, these findings confirm clinical reports indicating that buprenorphine decreases craving in both sexes and further indicate that it may be particularly effective at offsetting the heightened craving observed in women.

Interestingly, buprenorphine treatment during abstinence prevented weight gain over time, particularly in males. This is potentially important since weight gain is a common side effect of mu opioid receptor activation/agonist replacement therapy that can affect treatment outcome for OUD (Fenn et al. 2015; Huhn et al. 2019; Mysels and Sullivan 2010; Sanger and McCarthy 1981; Yeomans and Gray 2002). While methadone, the other FDA-approved agonist replacement medication for treating OUD, is associated with weight gain, especially in women (Fenn et al. 2015), it is unknown if treatment with buprenorphine would also be associated with weight gain (Schlienz et al. 2018). Given that buprenorphine is a partial agonist at mu receptors, it is possible that, unlike methadone, which is a full agonist, it may induce less weight gain. This idea is also consistent with previous findings showing that chronic buprenorphine treatment decreases sucrose intake (Hood et al. 2007; Mysels and Sullivan 2010; Mysels et al. 2011). One caveat, however, is that a recent clinical study of male patients undergoing treatment for OUD found a significant increase in body weight at the end of a 4-month buprenorphine-naloxone treatment period, although this difference was from the pre-treatment baseline and no controls were included (Baykara and Alban 2019). Further studies with appropriate controls are needed in both clinical and preclinical studies to understand the effect of buprenorphine treatment on body weight in males and females.

Together, these findings demonstrate the utility of our extended, IntA fentanyl self-administration procedure as a rat model of OUD that can be used to determine sex and hormonal influences on the development and treatment of OUD. This is critical since most of what is known about OUD has been derived from studies with males. There have also been surprisingly few preclinical studies examining sex differences in the efficacy of medications for OUD even though their use could greatly assist in resolving inconsistencies in human studies and teasing apart biological versus socio-cultural factors. Such studies could also provide critical sex-specific dosing information on the efficacy, behavioral specificity, and adverse effects of FDA-approved medications that could be translated to the clinic. Further research is also needed to screen new potential treatments since roughly $50 \%$ of individuals who enter opioid maintenance programs either drop out or are discharged early (Baekeland and Lundwall 1975; Hser et al. 2014), with even higher drop out/discharge rates for women (Anglin et al. 1987).

Acknowledgments This work was supported by NIDA grant R01DA024716 (W.J.L.). The University of Virginia Center for Research in Reproduction Ligand Assay and Analysis Core is supported by the Eunice Kennedy Shriver NICHD/NIH (NCTRI) Grant P50HD28934.

\section{Compliance with ethical standards}

Conflict of interest The authors declare that they have no competing interests.

\section{References}

Adelson M, Linzy S, Peles E (2018) Characteristics and outcome of male and female methadone maintenance patients: MMT in Tel Aviv and Las Vegas. Subst Use Misuse 53:230-238. https://doi.org/10.1080/ 10826084.2017.1298619

Ahmed S, Walker J, Koob GF (2000) Persistent increase in the motivation to take heroin in rats with a history of drug escalation. Neuropsychopharmacology 22:413-421. https://doi.org/10.1016/ S0893-133X(99)00133-5

Allain F, Samaha A (2019) Revisiting long-access versus short-access cocaine self-administration in rats: intermittent intake promotes addiction symptoms independent of session length. Addict Biol 24: 641-651. https://doi.org/10.1111/adb.12629

Allain F, Roberts DCS, Lévesque D, Samaha A-N (2017) Intermittent intake of rapid cocaine injections promotes robust psychomotor sensitization, increased incentive motivation for the drug and $\mathrm{mGlu} 2 / 3$ receptor dysregulation. Neuropharmacology 117:227-237. https:// doi.org/10.1016/j.neuropharm.2017.01.026

Allain F, Bouayad-Gervais K, Samaha A-N (2018) High and escalating levels of cocaine intake are dissociable from subsequent incentive motivation for the drug in rats. Psychopharmacology 235:317-328. https://doi.org/10.1007/s00213-017-4773-8

Ambrosio E, Martin S, Garcia-Lecumberri C, Crespo J (1999) The neurobiology of cannabinoid dependence: sex differences and potential interactions between cannabinoid and opioid systems. Life Sci 65: 687-694. https://doi.org/10.1016/s0024-3205(99)00291-x

American Medical Association (2020) Issue brief: Reports of increases in opioid-related overdose and other concerns during COVID pandemic

Anglin M, Hser Y, McGlothlin W (1987) Sex differences in addict careers. 2. Becoming addicted. Am J Drug Alcohol Abuse 13:59-71. https://doi.org/10.3109/00952998709001500

Awasaki Y, Nishida N, Sasaki S, Sato S (1997) Dopamine D(1) antagonist SCH23390 attenuates self-administration of both cocaine and fentanyl in rats. Environ Toxicol Pharmacol 3(2):115-122

Back S, Payne R, Wahlquist A, Carter R, Stroud Z, Haynes L, Hillhouse M, Brady K, Ling W (2011a) Comparative profiles of men and women with opioid dependence: results from a national multisite effectiveness trial. Am J Drug Alcohol Abuse 37:313-323. https:// doi.org/10.3109/00952990.2011.596982

Back SE, Lawson KM, Singleton LM, Brady KT (2011b) Characteristics and correlates of men and women with prescription opioid 
dependence. Addict Behav 36:829-834. https://doi.org/10.1016/j. addbeh.2011.03.013

Baekeland F, Lundwall L (1975) Dropping out of treatment: a critical review. Psychol Bull 82:738-783. https://doi.org/10.1037/ h0077132

Bass CE, Jansen HT, Roberts DCS (2010) Free-running rhythms of cocaine self-administration in rats held under constant lighting conditions. Chronobiol Int 27:535-548. https://doi.org/10.3109/ 07420521003664221

Baykara S, Alban K (2019) The effects of buprenorphine/naloxone maintenance treatment on sexual dysfunction, sleep and weight in opioid use disorder patients. Psychiatry Res 272:450-453. https://doi.org/ 10.1016/j.psychres.2018.12.153

Beiter RM, Peterson AB, Abel J, Lynch WJ (2016) Exercise during early, but not late abstinence, attenuates subsequent relapse vulnerability in a rat model. Transl Psychiatry 6:e792-e792. https://doi.org/10. 1038/tp.2016.58

Biscaia M, Fernández B, Higuera-Matas A, Miguéns M, Viveros M-P, García-Lecumberri C, Ambrosio E (2008) Sex-dependent effects of periadolescent exposure to the cannabinoid agonist CP-55,940 on morphine self-administration behaviour and the endogenous opioid system. Neuropharmacology 54:863-873. https://doi.org/10.1016/j. neuropharm.2008.01.006

Bossert JM, Kiyatkin E, Korah H, Hoots JK, Afzal A, Perekopskiy D et al (2020) In a rat model of opioid maintenance, the G-protein-biased MOR agonist TRV130 decreases relapse to oxycodone seeking and taking, and prevents oxycodone-induced brain hypoxia. Biol Psychiatry 88:935-944 in press

Brady LJ, Hofford RS, Tat J, Calipari ES, Kiraly DD (2019) Granulocytecolony stimulating factor alters the pharmacodynamic properties of cocaine in female mice. ACS Chem Neurosci 10:4213-4220. https://doi.org/10.1021/acschemneuro.9b00309

Calipari ES, Jones SR (2014) Sensitized nucleus accumbens dopamine terminal responses to methylphenidate and dopamine transporter releasers after intermittent-access self-administration. Neuropharmacology 82:1-10. https://doi.org/10.1016/j. neuropharm.2014.02.021

Calipari ES, Ferris MJ, Zimmer BA, Roberts DC, Jones SR (2013) Temporal pattern of cocaine intake determines tolerance vs sensitization of cocaine effects at the dopamine transporter. Neuropsychopharmacology 38:2385-2392. https://doi.org/10. 1038/npp.2013.136

Calipari ES, Ferris MJ, Siciliano CA, Zimmer BA, Jones SR (2014) Intermittent cocaine self-administration produces sensitization of stimulant effects at the dopamine transporter. J Pharmacol Exp Ther 349:192-198. https://doi.org/10.1124/jpet.114.212993

Calipari ES, Siciliano CA, Zimmer BA, Jones SR (2015) Brief intermittent cocaine self-administration and abstinence sensitizes cocaine effects on the dopamine transporter and increases drug seeking. Neuropsychopharmacology 40:728-735. https://doi.org/10.1038/ npp. 2014.238

Calipari ES, Juarez B, Morel C, Walker DM, Cahill ME, Ribeiro E, Roman-Ortiz C, Ramakrishnan C, Deisseroth K, Han M-H, Nestler EJ (2017) Dopaminergic dynamics underlying sex-specific cocaine reward. Nat Commun 8:13877. https://doi.org/10.1038/ ncomms 13877

Carroll ME, Campbell UC, Heideman P (2001) Ketoconazole suppresses food restriction-induced increases in heroin self-administration in rats: sex differences. Exp Clin Psychopharmacol 9(3):307-316

Carroll M, Morgan A, Lynch W, Campbell U, Dess N (2002) Intravenous cocaine and heroin self-administration in rats selectively bred for differential saccharin intake: phenotype and sex differences. Psychopharmacology 161:304-313. https://doi.org/10.1007/ s00213-002-1030-5

Chen SA, O'Dell LE, Hoefer ME, Greenwell TN, Zorrilla EP, Koob GF (2006) Unlimited access to heroin self-administration: independent motivational markers of opiate dependence. Neuropsychopharmacology 31:2692-2707. https://doi.org/10. 1038/sj.npp.1301008

Chopra M, Feldman Z, Mancino M, Oliveto A (2008) Sex and opioid maintenance dose influence response to naloxone in opioiddependent humans: a retrospective analysis. Pharmacol Biochem Behav 90:787-796. https://doi.org/10.1016/j.pbb.2008.05.023

Cicero TJ, Aylward SC, Meyer ER (2003) Gender differences in the intravenous self-administration of mu opiate agonists. Pharmacol Biochem Behav 74:541-549. https://doi.org/10.1016/S00913057(02)01039-0

Feder H (1981) Neuroendocrinology of reproduction: physiology and behavior. Springer, New York

Fenn JM, Laurent JS, Sigmon SC (2015) Increases in body mass index following initiation of methadone treatment. J Subst Abus Treat 51: 59-63. https://doi.org/10.1016/j.jsat.2014.10.007

Fragale JE, James MH, Aston-Jones G (2020) Intermittent selfadministration of fentanyl induces a multifaceted addiction state associated with persistent changes in the orexin system. Addict Biol:e12946

Fredriksson I, Applebey SV, Minier-Toribio A, Shekara A, Bossert JM, Shaham Y (2020) Effect of the dopamine stabilizer (-)-OSU6162 on potentiated incubation of opioid craving after electric barrierinduced voluntary abstinence. Neuropsychopharmacology. 45: $770-779$

Fulenwider HD, Nennig SE, Hafeez H, Price ME, Baruffaldi F, Pravetoni M, Cheng K, Rice KC, Manvich DF, Schank JR (2019) Sex differences in oral oxycodone self-administration and stress-primed reinstatement in rats. Addict Biol:e12822

Gancarz-Kausch AM, Adank DN, Dietz DM (2014) Prolonged withdrawal following cocaine self-administration increases resistance to punishment in a cocaine binge. Sci Rep 4:6876. https://doi.org/ 10.1038/srep06876

Gipson CD, Dunn KE, Bull A, Ulangkaya H, Hossain A (2020) Establishing preclinical withdrawal syndrome symptomatology following heroin self-administration in male and female rats. Exp Clin Psychopharmacol. https://doi.org/10.1037/pha0000375 Online ahead of print

González B, de Miguel R, Martín S, Pérez-Rosado A, Romero J, GarcíaLecumberri C, Fernández-Ruiz J, Ramos JA, Ambrosio E (2003) Effects of perinatal exposure to $\Delta 9$-tetrahydrocannabinol on operant morphine-reinforced behavior. Pharmacol Biochem Behav 75:577584. https://doi.org/10.1016/S0091-3057(03)00115-1

Gordon H (2019) Differential effects of addictive drugs on sleep and sleep stages. J Addict Res 3. https://doi.org/10.33140/JAR.03.02.01

Grella CE, Lovinger K (2012) Gender differences in physical and mental health outcomes among an aging cohort of individuals with a history of heroin dependence. Addict Behav 37:306-312. https://doi.org/10. 1016/j.addbeh.2011.11.028

Grimm JW, Hope BT, Wise RA, Shaham Y (2001) Neuroadaptation. Incubation of cocaine craving after withdrawal. Nature 412(6843): $141-142$

Gueye AB, Allain F, Samaha A-N (2019) Intermittent intake of rapid cocaine injections promotes the risk of relapse and increases mesocorticolimbic BDNF levels during abstinence. Neuropsychopharmacology 44:1027-1035. https://doi.org/10. 1038/s41386-018-0249-8

Haas AL, Peters RH (2000) Development of substance abuse problems among drug-involved offenders: evidence for the telescoping effect. J Subst Abus 12:241-253. https://doi.org/10.1016/S0899-3289(00) 00053-5

Hartwell EE, Pfeifer JG, McCauley JL, Moran-Santa Maria M, Back SE (2014) Sleep disturbances and pain among individuals with prescription opioid dependence. Addict Behav 39:1537-1542. https:// doi.org/10.1016/j.addbeh.2014.05.025 
Hecksher D, Hesse M (2009) Women and substance use disorders. Mens Sana Monogr 7:50-62. https://doi.org/10.4103/0973-1229.42585

Hedegaard H, Minino A, Warner M (2020) Drug overdose deaths in the United States, 1999-2018. NCHS Data Brief:1-8

Hemsing N, Greaves L, Poole N, Schmidt R (2016) Misuse of prescription opioid medication among women: a scoping review. Pain Res Manag 2016:1-8. https://doi.org/10.1155/2016/1754195

Herget G (2005) Methadone and buprenorphine added to the WHO list of essential medicines. HIV AIDS Policy Law Rev 10:23-24

Hernandez-Avila CA, Rounsaville BJ, Kranzler HR (2004) Opioid-, cannabis- and alcohol-dependent women show more rapid progression to substance abuse treatment. Drug Alcohol Depend 74:265272. https://doi.org/10.1016/j.drugalcdep.2004.02.001

Hirschtritt ME, Delucchi KL, Olfson M (2018) Outpatient, combined use of opioid and benzodiazepine medications in the United States, 1993-2014. Prev Med Rep 9:49-54. https://doi.org/10.1016/j. pmedr.2017.12.010

Hood S, Sorge RE, Stewart J (2007) Chronic buprenorphine reduces the response to sucrose-associated cues in non food-deprived rats. Pharmacol Biochem Behav 86:566-575. https://doi.org/10.1016/j. pbb.2007.01.020

Hser Y, Anglin M, McGlothlin W (1987a) Sex differences in addict careers. 3. Addiction. Am J Drug Alcohol Abuse 13:231-251. https://doi.org/10.3109/00952998709001512

Hser Y, Anglin M, McGlothlin W (1987b) Sex differences in addict careers. 1. Initiation of use. Am J Drug Alcohol Abuse 13:33-57. https://doi.org/10.3109/00952998709001499

Hser Y-I, Saxon AJ, Huang D, Hasson A, Thomas C, Hillhouse M, Jacobs P, Teruya C, McLaughlin P, Wiest K, Cohen A, Ling W (2014) Treatment retention among patients randomized to buprenorphine/naloxone compared to methadone in a multi-site trial: treatment retention on buprenorphine/methadone. Addiction 109: 79-87. https://doi.org/10.1111/add.12333

Huhn AS, Berry MS, Dunn KE (2019) Review: sex-based differences in treatment outcomes for persons with opioid use disorder. Am J Addict 28:246-261. https://doi.org/10.1111/ajad.12921

Jimenez-Treviño L, Saiz PA, García-Portilla MP, Díaz-Mesa EM, Sánchez-Lasheras F, Burón P, Casares MJ, Marina P, Gutiérrez E, Bobes J (2011) A 25-year follow-up of patients admitted to methadone treatment for the first time: mortality and gender differences. Addict Behav 36:1184-1190. https://doi.org/10.1016/j.addbeh. 2011.07.019

Johnson RE, Eissenberg T, Stitzer ML, Strain EC, Liebson IA, Bigelow GE (1995) Buprenorphine treatment of opioid dependence: clinical trial of daily versus alternate-day dosing. Drug Alcohol Depend 40: 27-35. https://doi.org/10.1016/0376-8716(95)01189-7

Johnson AR, Thibeault KC, Lopez AJ, Peck EG, Sands LP, Sanders CM, Kutlu MG, Calipari ES (2019) Cues play a critical role in estrous cycle-dependent enhancement of cocaine reinforcement. Neuropsychopharmacology 44:1189-1197. https://doi.org/10. 1038/s41386-019-0320-0

Jones HE, Fitzgerald H, Johnson RE, Jones HE, Fitzgerald H, Johnson RE (2005) Males and females differ in response to opioid agonist medications. Am J Addict 14:223-233. https://doi.org/10.1080/ 10550490590949569

Kawa AB, Robinson TE (2019) Sex differences in incentive-sensitization produced by intermittent access cocaine self-administration. Psychopharmacology 236:625-639. https://doi.org/10.1007/ s00213-018-5091-5

Kawa AB, Bentzley BS, Robinson TE (2016) Less is more: prolonged intermittent access cocaine self-administration produces incentivesensitization and addiction-like behavior. Psychopharmacology 233:3587-3602. https://doi.org/10.1007/s00213-016-4393-8

Kawa AB, Allain F, Robinson TE, Samaha A-N (2019) The transition to cocaine addiction: the importance of pharmacokinetics for preclinical models. Psychopharmacology 236:1145-1157. https:// doi.org/10.1007/s00213-019-5164-0

Kennedy AP, Epstein DH, Phillips KA, Preston KL (2013) Sex differences in cocaine/heroin users: drug-use triggers and craving in daily life. Drug Alcohol Depend 132:29-37. https://doi.org/10.1016/j. drugalcdep.2012.12.025

Kerstetter KA, Aguilar VR, Parrish AB, Kippin TE (2008) Protracted time-dependent increases in cocaine-seeking behavior during cocaine withdrawal in female relative to male rats. Psychopharmacology 198:63-75. https://doi.org/10.1007/s00213008-1089-8

Kimbrough A, Kononoff J, Simpson S, Kallupi M, Sedighim S, Palomino K, Conlisk D, Momper JD, de Guglielmo G, George O (2020) Oxycodone self-administration and withdrawal behaviors in male and female Wistar rats. Psychopharmacology 237:1545-1555. https://doi.org/10.1007/s00213-020-05479-y

Klein LC, Popke EJ, Grunberg NE (1997) Sex differences in effects of predictable and unpredictable footshock on fentanyl selfadministration in rats. Exp Clin Psychopharmacol 5:99-106. https://doi.org/10.1037//1064-1297.5.2.99

Koob GF (2020) Neurobiology of opioid addiction: opponent process, hyperkatifeia, and negative reinforcement. Biol Psychiatry 87:44 53. https://doi.org/10.1016/j.biopsych.2019.05.023

Koons AL, Rayl Greenberg M, Cannon RD, Beauchamp GA (2018) Women and the experience of pain and opioid use disorder: a literature-based commentary. Clin Ther 40:190-196. https://doi. org/10.1016/j.clinthera.2017.12.016

Kunko PM, French D, Izenwasser S (1998) Alterations in locomotor activity during chronic cocaine administration: effect on dopamine receptors and interaction with opioids. J Pharmacol Exp Ther 285: 277-284

Lacy RT, Strickland JC, Feinstein MA, Robinson AM, Smith MA (2016) The effects of sex, estrous cycle, and social contact on cocaine and heroin self-administration in rats. Psychopharmacology 233:32013210. https://doi.org/10.1007/s00213-016-4368-9

Lacy RT, Austin BP, Strickland JC (2020) The influence of sex and estrous cyclicity on cocaine and remifentanil demand in rats. Addict Biol 25:e12716. https://doi.org/10.1111/adb.12716

Levine AR, Lundahl LH, Ledgerwood DM, Lisieski M, Rhodes GL, Greenwald MK (2015) Gender-specific predictors of retention and opioid abstinence during methadone maintenance treatment. J Subst Abus Treat 54:37-43. https://doi.org/10.1016/j.jsat.2015.01.009

Lewis B, Hoffman LA, Nixon SJ (2014) Sex differences in drug use among polysubstance users. Drug Alcohol Depend 145:127-133. https://doi.org/10.1016/j.drugalcdep.2014.10.003

Lofwall MR, Nuzzo PA, Walsh SL (2012) Effects of cold pressor pain on the abuse liability of intranasal oxycodone in male and female prescription opioid abusers. Drug Alcohol Depend 123(1-3):229-238

Logan RW, Williams WP, McClung CA (2014) Circadian rhythms and addiction: mechanistic insights and future directions. Behav Neurosci 128:387-412. https://doi.org/10.1037/a0036268

Lynch WJ (2008) Acquisition and maintenance of cocaine selfadministration in adolescent rats: effects of sex and gonadal hormones. Psychopharmacology 197:237-246. https://doi.org/10. 1007/s00213-007-1028-0

Lynch WJ (2009) Sex and ovarian hormones influence vulnerability and motivation for nicotine during adolescence in rats. Pharmacol Biochem Behav 94:43-50. https://doi.org/10.1016/j.pbb.2009.07. 004

Lynch WJ (2018) Modeling the development of drug addiction in male and female animals. Pharmacol Biochem Behav 164:50-61. https:// doi.org/10.1016/j.pbb.2017.06.006

Lynch WJ, Carroll ME (1999) Sex differences in the acquisition of intravenously self-administered cocaine and heroin in rats. Psychopharmacology 144:77-82. https://doi.org/10.1007/ s002130050979 
Lynch WJ, Taylor JR (2004) Sex differences in the behavioral effects of 24-h/day access to cocaine under a discrete trial procedure. Neuropsychopharmacology 29:943-951. https://doi.org/10.1038/ sj.npp.1300389

Lynch WJ, Tan L, Narmeen S, Beiter R, Brunzell DH (2019) Exercise or saccharin during abstinence block estrus-induced increases in nicotine-seeking. Physiol Behav 203:33-41. https://doi.org/10.1016/j. physbeh.2017.10.026

Marchand K, Palis H, Peng D, Fikowski J, Harrison S, Spittal P, Schechter MT, Oviedo-Joekes E (2015) The role of gender in factors associated with addiction treatment satisfaction among long-term opioid users. J Addict Med 9:391-398. https://doi.org/10.1097/ ADM.0000000000000145

Marsh K, Simpson D (1986) Sex-differences in opioid addiction careers. Am J Drug Alcohol Abuse 12:309-329. https://doi.org/10.3109/ 00952998609016873

Marsh JC, Park K, Lin Y-A, Bersamira C (2018) Gender differences in trends for heroin use and nonmedical prescription opioid use, 20072014. J Subst Abus Treat 87:79-85. https://doi.org/10.1016/j.jsat. 2018.01.001

Martin TJ, Kim SA, Harris LS, Smith JE (1997) Potent reinforcing effects of dihydroetorphine in rats. Eur J Pharmacol 324(2-3):141-145

Martin DA, Gyawali U, Calu DJ (2020) Effects of 5-HT2A receptor stimulation on economic demand for fentanyl after intermittent and continuous access self-administration in male rats. Addict Biol:e12926. https://doi.org/10.1111/adb.12926

Mattick RP, Breen C, Kimber J, Davoli M (2014) Buprenorphine maintenance versus placebo or methadone maintenance for opioid dependence. Cochrane Database Syst Rev. https://doi.org/10.1002/ 14651858.CD002207.pub4

Mavrikaki M, Pravetoni M, Page S, Potter D, Chartoff E (2017) Oxycodone self-administration in male and female rats. Psychopharmacology 234:977-987. https://doi.org/10.1007/ s00213-017-4536-6

Mazure CM, Fiellin DA (2018) Women and opioids: something different is happening here. Lancet 392:9-11. https://doi.org/10.1016/S01406736(18)31203-0

McHugh RK, DeVito EE, Dodd D, Carroll KM, Potter JS, Greenfield SF, Connery HS, Weiss RD (2013) Gender differences in a clinical trial for prescription opioid dependence. J Subst Abus Treat 45:38-43. https://doi.org/10.1016/j.jsat.2012.12.007

Meade CS, Weiss RD, Fitzmaurice GM, Poole SA, Subramaniam GA, Patkar AA, Connery HS, Woody GE (2010) HIV risk behavior in treatment-seeking opioid-dependent youth: results from a NIDA clinical trials network multisite study. J AIDS J Acquir Immune Defic Syndr 55:65-72. https://doi.org/10.1097/QAI. 0b013e3181d916db

Moran LM, Kowalczyk WJ, Phillips KA, Vahabzadeh M, Lin J-L, Mezghanni M, Epstein DH, Preston KL (2018) Sex differences in daily life stress and craving in opioid-dependent patients. Am J Drug Alcohol Abuse 44:512-523. https://doi.org/10.1080/00952990. 2018.1454934

Morgan AD, Campbell UC, Fons RD, Carroll ME (2002) Effects of agmatine on the escalation of intravenous cocaine and fentanyl self-administration in rats. Pharmacol Biochem Behav 72(4):873880

Mysels DJ, Sullivan MA (2010) The relationship between opioid and sugar intake: review of evidence and clinical applications. J Opioid Manag 6:445-452. https://doi.org/10.5055/jom.2010.0043

Mysels DJ, Vosburg S, Benga I, Levin FR, Sullivan MA (2011) Course of weight change during naltrexone vs methadone maintenance for opioid-dependent patients 12

National Survey on Drug Use and Health (2020) Concatenated public use file (2002 to 2018). https://pdas.samhsa.gov/\#/ Accessed Feb 2020

Nicolas C, Russell TI, Pierce AF, Maldera S, Holley A, You Z-B, McCarthy MM, Shaham Y, Ikemoto S (2019) Incubation of cocaine craving after intermittent-access self-administration: sex differences and estrous cycle. Biol Psychiatry 85:915-924. https://doi.org/10. 1016/j.biopsych.2019.01.015

Nishida N, Hasegawa Y, Chiba S, Wakimasu M, Fujino M (1989) Reinforcing effects of the enkephalin analogs, EK-209 and EK399, in rats. Eur J Pharmacol 166(3):453-458

O’Dell L, Chen S, Smith R, Specio S, Balster R, Paterson N, Markou A, Zorrilla E, Koob G (2007) Extended access to nicotine selfadministration leads to dependence: circadian measures, withdrawal measures, and extinction behavior in rats. J Pharmacol Exp Ther 320:180-193. https://doi.org/10.1124/jpet.106.105270

O’Neal TJ, Nooney MN, Thien K, Ferguson SM (2020) Chemogenetic modulation of accumbens direct or indirect pathways bidirectionally alters reinstatement of heroin-seeking in high- but not low-risk rats. Neuropsychopharmacol. 45:1251-1262. https://doi.org/10.1038/ s41386-019-0571-9

Office of Women's Health (2017) Final report: Opioid use, misuse, and overdose in women

Öhlin L, Fridell M, Nyhlén A (2015) Buprenorphine maintenance program with contracted work/education and low tolerance for nonprescribed drug use: a cohort study of outcome for women and men after seven years. BMC Psychiatry 15:56. https://doi.org/10. 1186/s12888-015-0415-Z

Palis H, Marchand K, Guh D, Brissette S, Lock K, MacDonald S, Harrison S, Anis AH, Krausz M, Marsh DC, Schechter MT, Oviedo-Joekes E (2017) Men's and women's response to treatment and perceptions of outcomes in a randomized controlled trial of injectable opioid assisted treatment for severe opioid use disorder. Subst Abuse Treat Prev Policy 12:25. https://doi.org/10.1186/ s13011-017-0110-9

Pérez de los Cobos J, Siñol N, Trujols J, del Río E, Bañuls E, Luquero E, Menoyo A, Queraltó JM, Baiget M, Álvarez E (2007) Association of CYP2D6 ultrarapid metabolizer genotype with deficient patient satisfaction regarding methadone maintenance treatment. Drug Alcohol Depend 89:190-194. https://doi.org/10.1016/j.drugalcdep. 2006.12.018

Perry AN, Westenbroek C, Becker JB (2013) The development of a preference for cocaine over food identifies individual rats with addiction-like behaviors. PLoS ONE 8:e79465. https://doi.org/10. 1371/journal.pone.0079465

Peterson AB, Hivick DP, Lynch WJ (2014) Dose-dependent effectiveness of wheel running to attenuate cocaine-seeking: impact of sex and estrous cycle in rats. Psychopharmacology 231:2661-2670. https://doi.org/10.1007/s00213-014-3437-1

Phillips AG, McGovern DJ, Lee S, Ro K, Huynh DT, Elvig SK, Fegan $\mathrm{KN}$, Root DH (2019) Oral prescription opioid-seeking behavior in male and female mice. Addict Biol Sep 5:e12828. https://doi.org/10. $1111 / \mathrm{adb} .12828$

Rada P, Jensen K, Hoebel B (2001) Effects of nicotine and mecamylamine-induced withdrawal on extracellular dopamine and acetylcholine in the rat nucleus accumbens. Psychopharmacology 157:105-110. https://doi.org/10.1007/s002130100781

Ramôa CP, Doyle SE, Naim DW, Lynch WJ (2013) Estradiol as a mechanism for sex differences in the development of an addicted phenotype following extended access cocaine self-administration. Neuropsychopharmacology 38:1698-1705. https://doi.org/10. 1038/npp.2013.68

Ramôa CP, Doyle SE, Lycas MD, Chernau AK, Lynch WJ (2014) Diminished role of dopamine D1-receptor signaling with the development of an addicted phenotype in rats. Biol Psychiatry 76:8-14. https://doi.org/10.1016/j.biopsych.2013.09.028

Reichel CM, Chan CH, Ghee SM, See RE (2012) Sex differences in escalation of methamphetamine self-administration: cognitive and motivational consequences in rats. Psychopharmacology 223:371380. https://doi.org/10.1007/s00213-012-2727-8 
Reiner DJ, Lofaro OM, Applebey SV, Korah H, Venniro M, Cifani C, Bossert JM, Shaham Y (2020) Role of projections between Piriform cortex and orbitofrontal cortex in relapse to fentanyl seeking after palatable food choice-induced voluntary abstinence. J Neurosci 40: 2485-2497

Roberts DCS, Brebner K, Vincler M, Lynch WJ (2002) Patterns of cocaine self-administration in rats produced by various access conditions under a discrete trials procedure. Drug Alcohol Depend 67: 291-299. https://doi.org/10.1016/S0376-8716(02)00083-2

Rutherford MJ, Cacciola JS, Alterman AI, Cook TG (1997) Social competence in opiate-addicted individuals: gender differences, relationship to psychiatric diagnoses, and treatment response. Addict Behav 22:419-425. https://doi.org/10.1016/S0306-4603(96)00027-5

Sanchez V, Moore CF, Brunzell DH, Lynch WJ (2014) Sex differences in the effect of wheel running on subsequent nicotine-seeking in a rat adolescent-onset self-administration model. Psychopharmacology 231:1753-1762. https://doi.org/10.1007/s00213-013-3359-3

Sanger D, McCarthy P (1981) Increased food and water intake produced in rats by opiate receptor agonists. Psychopharmacology (Berlin) 74: 217-220

Santoro GC, Carrion J, Patel K, Vilchez C, Veith J, Brodie JD, Dewey SL (2017) Sex differences in regional brain glucose metabolism following opioid withdrawal and replacement. Neuropsychopharmacology 42:1841-1849. https://doi.org/10.1038/npp.2017.69

Sartor CE, Kranzler HR, Gelernter J (2014) Rate of progression from first use to dependence on cocaine or opioids: a cross-substance examination of associated demographic, psychiatric, and childhood risk factors. Addict Behav 39:473-479. https://doi.org/10.1016/j. addbeh.2013.10.021

Schlienz NJ, Huhn AS, Speed TJ, Sweeney MM, Antoine DG (2018) Double jeopardy: a review of weight gain and weight management strategies for psychotropic medication prescribing during methadone maintenance treatment. Int Rev Psychiatry 30(5):147-154. https://doi.org/10.1080/09540261.2018.1509843

Schottenfeld R, Pakes J, Kosten T (1998) Prognostic factors in buprenorphine- versus methadone-maintained patients. J Nerv Ment Dis 186:35-43

Singer BF, Fadanelli M, Kawa AB, Robinson TE (2017) Are cocaineseeking "habits" necessary for the development of addiction-like behavior in rats? J Neurosci 38:2458-2417. https://doi.org/10. 1523/JNEUROSCI.2458-17.2017

Smethells JR, Greer A, Dougen B, Carroll ME (2020) Effects of voluntary exercise and sex on multiply-triggered heroin reinstatement in male and female rats. Psychopharmacology 237:453-463. https:// doi.org/10.1007/s00213-019-05381-2

Sorge RE, Stewart J (2006) The effects of chronic buprenorphine on intake of heroin and cocaine in rats and its effects on nucleus accumbens dopamine levels during self-administration. Psychopharmacology 188:28-41. https://doi.org/10.1007/s00213006-0485-1

Sorge RE, Rajabi H, Stewart J (2005) Rats maintained chronically on buprenorphine show reduced heroin and cocaine seeking in tests of extinction and drug-induced reinstatement. Neuropsychopharmacology 30:1681-1692. https://doi.org/10. 1038/sj.npp.1300712

Stewart J, Woodside B, Sraham Y (1996) Ovarian honnones do not affect the initiation and maintenance of intravenous self-administration of heroin in the female rat. Psychobiology 24:154-159. https://doi.org/ 10.3758/BF03331967

Thorpe D, Lacy RT, Strickland JC (2020) Acquisition of remifentanil self-administration: Enhanced in female rats but no effect of adolescent stress exposure. Pharmacol Biochem Behav 199:173038. https://doi.org/10.1016/j.pbb.2020.173038
Towers EB, Tunstall BJ, McCracken ML, Vendruscolo LF, Koob GF (2019) Male and female mice develop escalation of heroin intake and dependence following extended access. Neuropharmacology 151:189-194. https://doi.org/10.1016/j.neuropharm.2019.03.019

Townsend EA, Negus SS, Caine SB, Thomsen M, Banks ML (2019) Sex differences in opioid reinforcement under a fentanyl vs. food choice procedure in rats. Neuropsychopharmacology 44:2022-2029. https://doi.org/10.1038/s41386-019-0356-1

Tuchman E (2010) Women and addiction: the importance of gender issues in substance abuse research. J Addict Dis 29:127-138. https://doi.org/10.1080/10550881003684582

Vann RE, Balster RL, Beardsley PM (2006) Dose, duration, and pattern of nicotine administration as determinants of behavioral dependence in rats. Psychopharmacology 184:482-493. https://doi.org/10.1007/ s00213-005-0037-0

Vazquez M, Frazier JH, Reichel CM, Peters J (2020) Acute ovarian hormone treatment in freely cycling female rats regulates distinct aspects of heroin seeking. Learn Mem 27:6-11. https://doi.org/10. $1101 / \mathrm{lm} .050187 .119$

Vela G, Martın S, Garcia-Gil L, Crespo JA, Ruiz-Gayo M, FernandezRuiz JJ, Garcia-Lecumberri C, Pelaprat D, Fuentes JA, Ramos JA, Ambrosio E (1998) Maternal exposure to D9-tetrahydrocannabinol facilitates morphine self-administration behavior and changes regional binding to central $\mathrm{m}$ opioid receptors in adult offspring female rats. Brain Res 807:101-109. https://doi.org/10.1016/s00068993(98)00766-5

Venniro M, Zhang M, Shaham Y, Caprioli D (2017) Incubation of methamphetamine but not heroin craving after voluntary abstinence in male and female rats. Neuropsychopharmacology 42:1126-1135. https://doi.org/10.1038/npp.2016.287

Venniro M, Zhang M, Caprioli D, Hoots JK, Golden SA, Heins C, Morales M, Epstein DH, Shaham Y (2018) Volitional social interaction prevents drug addiction in rat models. Nat Neurosci 21:1520 1529. https://doi.org/10.1038/s41593-018-0246-6

Venniro M, Russell TI, Zhang M, Shaham Y (2019) Operant social reward decreases incubation of heroin craving in male and female rats. Biol Psychiatry 86:848-856

Yeomans MR, Gray RW (2002) Opioid peptides and the control of human ingestive behaviour. Neurosci Biobehav Rev 26:713-728. https://doi.org/10.1016/S0149-7634(02)00041-6

Yu J, Zhang S, Epstein DH, Fang Y, Shi J, Qin H, Yao S, le Foll B, Lu L (2007) Gender and stimulus difference in cue-induced responses in abstinent heroin users. Pharmacol Biochem Behav 86:485-492

Zacny JP (2002) Gender differences in opioid analgesia in human volunteers: cold pressor and mechanical pain. NIDA Res Monogr 182:2223

Zhang Y, Liang Y, Randesi M, Yuferov V, Zhao C, Kreek MJ (2018) Chronic oxycodone self-administration altered reward-related genes in the ventral and dorsal striatum of C57BL/6J mice: an RNA-seq analysis. Neuroscience 393:333-349

Zielinski L, Bhatt M, Sanger N, Plater C, Worster A, Varenbut M, Daiter J, Pare G, Marsh DC, Desai D, MacKillop J, Steiner M, McDermid Vaz S, Thabane L, Samaan Z (2017) Association between cannabis use and methadone maintenance treatment outcomes: an investigation into sex differences. Biol Sex Differ 8:8. https://doi.org/10. 1186/s13293-017-0130-1

Zimmer BA, Oleson EB, Roberts DC (2012) The motivation to selfadminister is increased after a history of spiking brain levels of cocaine. Neuropsychopharmacology 37:1901-1910. https://doi. org/10.1038/npp.2012.37

Publisher's note Springer Nature remains neutral with regard to jurisdictional claims in published maps and institutional affiliations. 